Research Article

\title{
Investigating the Failure Mechanism of Jointed Rock Slopes Based on Discrete Element Method
}

\author{
Chao Peng $\mathbb{D}^{1,2}$ Qifeng Guo, ${ }^{3}$ Zhenxiong Yan, ${ }^{4}$ Minglong Wang, ${ }^{2}$ and Jiliang Pan $^{3}$ \\ ${ }^{1}$ Harbin Institute of Technology, Shenzhen 518055, China \\ ${ }^{2}$ Real Estate Assessment Center, Shenzhen 518040, China \\ ${ }^{3}$ School of Civil and Resource Engineering, University of Science and Technology Beijing, Beijing 100083, China \\ ${ }^{4}$ College of Vanadium and Titanium, Panzhihua University, Panzhihua, Sichuan 617000, China \\ Correspondence should be addressed to Chao Peng; pcisatc@hotmail.com
}

Received 19 June 2020; Revised 10 August 2020; Accepted 24 August 2020; Published 12 September 2020

Academic Editor: Fengqiang Gong

Copyright (C) 2020 Chao Peng et al. This is an open access article distributed under the Creative Commons Attribution License, which permits unrestricted use, distribution, and reproduction in any medium, provided the original work is properly cited.

\begin{abstract}
This paper presents a comprehensive engineering method to investigate the failure mechanism of the jointed rock slopes. The field geology survey is first carried out to obtain the slope joint data. A joint network model considering the structural complexity of rock mass is generated in the PFC software. The synthetic rock mass (SRM) approach for simulating the mechanical behavior of jointed rock mass is employed, in which the flat-jointed bonded-particle model (FJM) and smooth joint contact model (SJM) represent intact rock and joints, respectively. Subsequently, the effect of microparameters on macromechanical properties of rock is investigated for parameter calibration. Moreover, the scale effect is analyzed by multiscale numerical tests, and the representative elementary volume (REV) size in the selected research area is found as $16 \mathrm{~m} \times 16 \mathrm{~m} \times 16 \mathrm{~m}$. The microparameters of the SRM model are calibrated to match the mechanical properties of the engineering rock mass. Finally, an engineering case from Shuichang open-pit mine is analyzed and the failure process of the slope during the excavation process from micro- to macroscale is obtained. It has been found that failure occurs at the bottom of the slope and gradually develops upwards. The overall failure of the slope is dominated by the shallow local tension fracture and wedge failure.
\end{abstract}

\section{Introduction}

The rock mass is a geological body with fractures complexly distributed. These natural discontinuities such as joints and faults are ubiquitous in rock, which have an important impact on the mechanical behaviors of rock material and lead to the anisotropy, heterogeneity, and scale effect [1]. The mechanical properties and failure mechanism of the rock mass are always a major field of rock mechanics. The accurate description of geometrical characteristics of joint network is critical for the safe design, construction, and stability analysis in rock mass engineering. Moreover, investigating the mechanical properties and failure mechanism of jointed rock from micromechanical viewpoint can both enrich rock mass theory and guide the rock engineering practice.

Considerable research studies have been carried out on the joint network modelling and analysis methods of jointed rock mass [2-19]. Due to the complexity and uncertainty of joints system in the rock, the stochastic approach based on the theories of probability and statistics is widely used to describe joint geometries from limited measurements such as borehole logging and scanline [2], which is also the mathematical theoretical basis of numerical simulation of joint network. Beacher et al. [3, 4] assumed joints to be planar discs and considered the geometrical properties (e.g., spacing, size, and aperture) as independent random variables obeying certain probability distributions. Hudson and Priest [5], Priest and Hudson [6, 7], and Rives et al. [8] arrived at the conclusion that joint spacing usually followed a negative exponential, lognormal, or normal distribution depending on the degree of joint saturation in the network. Similarly, the properties of frequency [9], size [10, 11], and aperture [12, 13] were analyzed based on geological survey. Einstein and Baecher [14] processed measurement data using a rosette or stereogram to 
group the joints into different sets with their orientation feature by a uniform, normal, or Fisher distribution. Hammah et al. [15-19] presented separately different data analysis methods for optimized and determined dominant orientations, which promoted the progress of statistical method of joint. Three-dimensional modelling and analysis numerical methods have been developed with the computer-aided technology in the past two decades [20-22]. Xi et al. [23] investigated the initiation and propagation of precracks in rock. Einstein and Locsin [24] and Ivanova et al. [25] proposed 2D or 3D fracture simulation models, which promoted the application of modelling theory.

Particle-based models, which were originally introduced by Cundall and Strack [26] to simulate granular materials (e.g., soils and sands) and which gradually evolved to commercial code, i.e., particle flow code (PFC) [27], are now widely used for jointed rock mass. Conventional PFC modelling of intact rock considers the bonded-particle model (BPM) [28], which has two limitations, i.e., an unreasonable UCS/TS (compressive to tensile strength) ratio and low friction angle. Some options were suggested to solve these problems: changing the particle size distribution to reduce the porosity $[29,30]$ or changing particle shape into cluster [28] and clumps [31]. Potyondy et al. [32] created a new model, flat-jointed bonded-particle model (FJM), to overcome these limitations and used it to reproduce a realistic hard rock. To suppress such an artificial roughness, smooth joint contact model (SJM), which was independent of the arrangement of local particles in contact, was proposed to simulate the geometric-mechanical characteristics of joints [33]. Based on the two well-established techniques, BPM and SJM, Ivars et al. [33] and Pierce et al. [34] developed a synthetic rock mass (SRM) to represent the mechanical behaviors of jointed rock mass and obtained the scale effect, anisotropy, and brittleness that cannot be obtained using empirical methods of property estimation. The uses of SRM are mostly related to simulating crack propagation and the slip of rock mass under selected loading conditions, such as direct shear test [35-39] and uniaxial and triaxial compression test [40-42]. Some researchers employed SRM to study the effect of sample size on rock mass strength and derive the equivalent rock mass properties [43-45]. SRM was also used to simulate the mechanical properties and failure mechanism of rock mass in engineering projects [46-49]. However, due to complicated geometry of joints, SRM has rarely been used for the slope stability analysis of open-pit mine and the failure mechanisms of jointed rock slope during the ore excavation have not been fully understood.

The remainder of this paper is organized as follows. Section 2 reviews the main aspects and methodology of the components of SRM. In section 3, based on the statistic characteristics of joints, a numerical model of the jointed rock mass is built by PFC software. In section 4 , the microparameters of FJM and SJM are calibrated to reproduce the macroparameters derived from laboratory tests. Then, multiscale SRM models are established to investigate the scale effect and determine the representative elementary volume (REV) size by numerical tests. Next, the microparameters are recalibrated to represent the behaviors of rock mass according to the REV size and Hoek-Brown method. In Section 5, a jointed slope of Shuichang open-pit iron mine is selected as an engineering case, and the failure mechanism and evolution process of the slope are analyzed from a micromechanical viewpoint.

\section{Methodology}

2.1. Synthetic Rock Mass (SRM) in PFC. The synthetic rock mass (SRM) approach has been implemented in PFC software, where particles are rigid spherical bodies joined by deformable contacts, to solve problems by using the explicit formulation of the distinct element method (DEM). This new technique can be used as a virtual laboratory to conduct numerical experiments to represent in a qualitative and quantitative mechanical behavior of jointed rock mass and has already made it possible to extend the volumes of rock at the scale of 10-100 m containing thousands of nonpersistent joints. In PFC software, the SRM brings together two wellestablished techniques: bonded-particle model for intact rock deformation and fracture and discrete fracture network (DFN) for joints. That is to say, the SRM model represents the jointed rock mass as an assembly of intact rock and an embedded DFN. The main components of SRM sample are shown in Figure 1. The following section presents the main aspects of each model.

\subsection{Representation of the Intact Rock. FJM (flat-jointed} bonded-particle model) was proposed based on the distinct element method to simulate the mechanical behavior of intact rock in PFC software by Potyondy [32]. This model can overcome the limitations of the standard BPM model and well explain the mechanical behavior of various aspects of rock, especially for hard rock. In FJM, the intact rock is represented as assemblage of rigid circular (in 2D) or spherical (in 3D) particles and piece of finite-size interface between two notional surfaces. A typical flat joint contact (Figure 2) can be deformed, partially damaged, and broken by the influence of external force. The particle can be considered as a skirted particle, which can provide interlocking and rotational resistance even after the interface breaking. Therefore, a more reasonable unconfined compressive to tensile strength (UCS/TS) ratio for hard rock can be obtained through FJM.

2.3. Representation of the DFN. The smooth joint contact model (SJM) simulates the behavior of a smooth interface, regardless of the local particle contact orientations along the interface [33]. This kind of contact is described as smooth because particle pairs joined by a smooth joint contact may overlap and "slide" past each other, instead of being forced to move around one another (Figure 3).

A smooth joint can be envisioned as a set of elastic springs uniformly distributed over a circular cross section, centered at the contact point and oriented parallel with the 


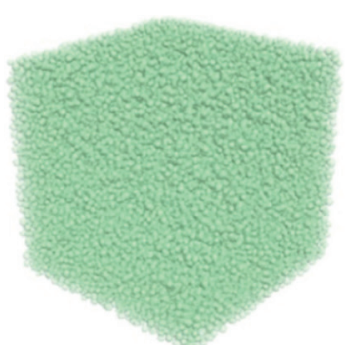

(a)

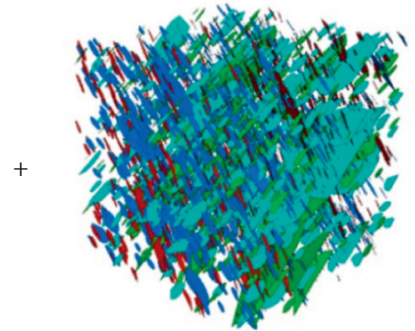

(b)

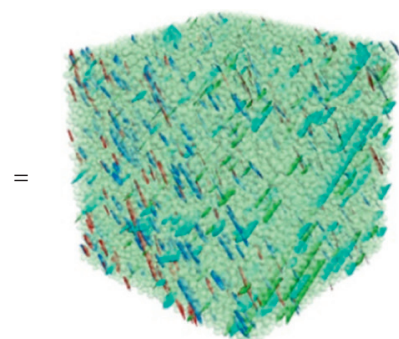

(c)

FIGURE 1: Synthetic rock mass basic components: (a) intact rock; (b) DFN; (c) SRM.

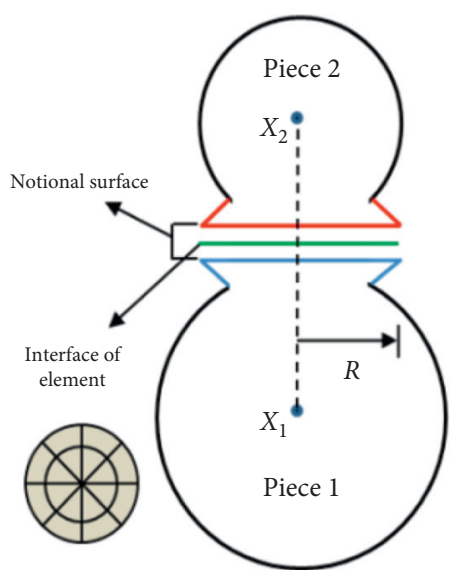

Figure 2: A typical schematic diagram of flat joint contact.

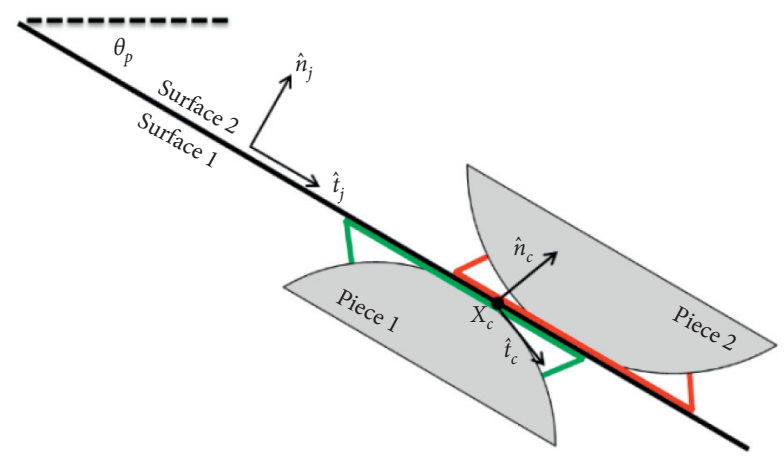

FIgUre 3: A smooth joint model (from PFC software manual [27]).

joint plane. The area of the smooth-joint cross section is given by

$$
A=\pi\left(\lambda \min \left(R^{(1)}, R^{(2)}\right)\right)^{2},
$$

where $R^{(1)}$ and $R^{(2)}$ are the particle radii and $\lambda$ is the radius multiplier.

When the unbonded SJM model is specified, the incremental force calculation is performed depending on the elastic portion of the displacement increment $\left(\Delta U_{n}^{e}\right.$ and $\left.\Delta U_{s}^{e}\right)$.

$$
\begin{aligned}
F_{n} & =\left(F_{n}\right)_{0}+k_{n} A \Delta U_{n}^{e}, \\
F_{s}^{*} & =\left(F_{s}\right)_{0}-k_{s} A \Delta U_{s}^{e},
\end{aligned}
$$

where $k_{n}$ and $k_{s}$ are the normal and shear stiffness, respectively, and $\left(F_{n}\right)_{0}$ and $\left(F_{s}\right)_{0}$ are the smooth joint normal force and shear force at the beginning of the timestep, respectively.

If $\left|F_{s}^{*}\right| \leq \mu F_{n}$, then $F_{s}=F_{s}^{*}$. Otherwise, $F_{s}=\mu F_{n}$, sliding is assumed to occur. While slipping, shear displacements produce an increase in normal force due to dilation:

$$
F_{n}=\left(F_{n}\right)_{0}+\left[\frac{\left|F_{s}^{\prime}\right|-F_{s}^{*}}{k_{s}}\right] k_{n} \tan \psi,
$$

where $\mu$ is the friction coefficient and $\psi$ is the dilation angle.

\section{Construction of Complex Joint Network Model}

3.1. Geometrical Characteristics of Joints. The natural joints often comprise complex network and dominate the mechanical behaviors of jointed rock mass. Therefore, it is important to obtain the geometrical characteristic representation of complex two or three-dimensional joint network for modelling jointed rock mass. However, it is impossible to directly obtain the in situ joint data deep in the rock. The details of 3D structures of joint network are usually inferred from the observation information of lower dimensional limited exposures like borehole logging, outcrop scanline, or window mapping. A large number of field survey data show that the joints in the rock mass mostly appear in sets, and it is necessary to identify the dominant sets of joints which highly affect the mechanical behavior of rock.

In this paper, a field survey was carried out in the north of Shuichang open-pit iron mine by using borehole logging and scanline methods. A total of 311 sets of joint are measured, and the data show that joints in this area are well developed. In addition, some joints have potential adverse effects on slope stability because the strike and dip direction of joints are almost the same with those of the slope. Statistical analyses are conducted on the data by using rose diagram or stereogram so that joints can be grouped into different sets with their orientations (Figure 4).

By using the hierarchical cluster method, the measured data were grouped into four dominant orientations, namely, $\mathrm{A}, \mathrm{B}, \mathrm{C}$, and D (Table 1). And the number of joints in these four orientations is 248 , accounting for $79.7 \%$ of the total.

The characteristic of distribution of joints can be described by geometric parameters such as dip direction, dip angle, and spacing. To provide necessary information for the 


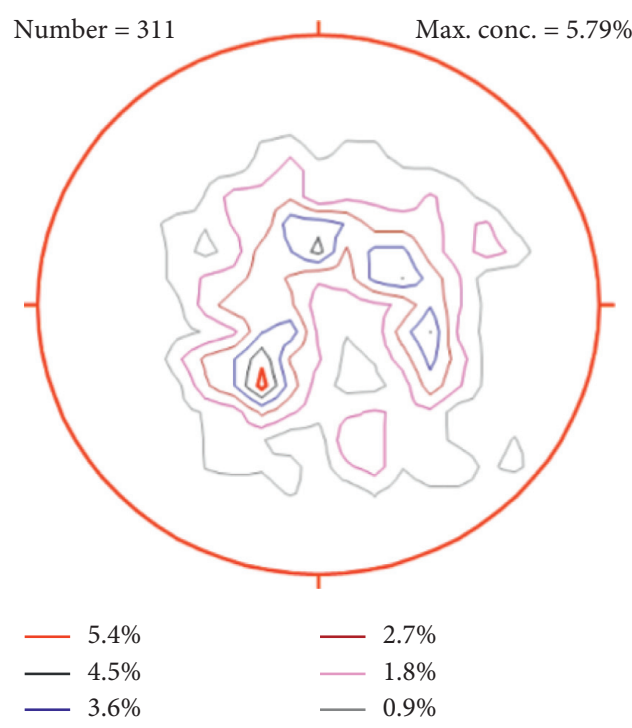

(a)

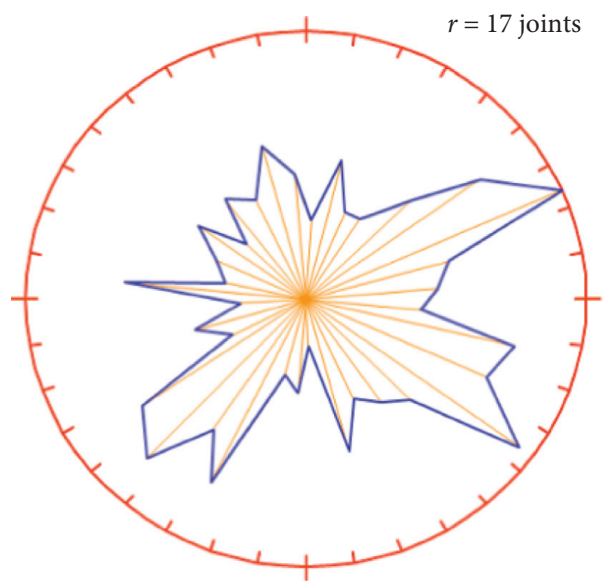

(b)

FIgURE 4: Statistical analysis results: (a) contour plot of the joint plane; (b) rose diagram of dip direction.

TABLE 1: Range of dominant orientations.

\begin{tabular}{lcccc}
\hline ID & A & B & C & D \\
\hline Dip direction $\left(^{\circ}\right)$ & $40-70$ & $100-170$ & $210-240$ & $280-340$ \\
Dip angle $\left(^{\circ}\right)$ & $13-75$ & $19-86$ & $25-77$ & $19-69$ \\
Number & 56 & 78 & 61 & 53 \\
\hline
\end{tabular}

subsequent establishment of joint network model, probability distribution modes of those parameters are studied with orientation characterized by a uniform, normal, or negative exponential distribution, and the histogram and fitting curve are shown in Figure 5.

The basic parameters and distributions for dominant orientations in Shuichang open-pit iron mine are obtained as shown in Table 2.

3.2. Generation and Testing of Joint Network Model. The shape of the joint in three-dimensional model is regarded as planar discs of radius in PFC. In this case, the probability density function of the disc's radius is calculated as

$$
f_{r}(r)=\frac{\pi}{2 \lambda} e^{-(\pi / 2 \lambda) r}
$$

where $\lambda$ is the mean value of negative exponential function.

The mean radius of joint disc is given as

$$
\bar{r}=\int_{0}^{\infty} r f_{r}(r) d r=\int_{0}^{\infty} r \frac{\pi}{2 \lambda} e^{-(\pi / 2 \lambda) r} d r=\frac{2 \lambda}{\pi}=\frac{2 \bar{l}}{\pi},
$$

where $\bar{r}$ is the mean radius of joint disc and $\bar{l}$ is the mean trace length.

In a relatively homogeneous area, the volume density is independent of direction and relatively constant and has the following relationship with the average linear density [50]:

$$
\bar{\lambda}_{d}=2 \pi \lambda_{V} \int_{0}^{\infty} d \int_{d}^{\infty} f(r) \mathrm{d} r \mathrm{~d} d
$$

Based on formulas (4) and (6), the volume density of the joint with the radius approximately complied with the negative exponential distribution can be obtained as

$$
\lambda_{V}=\frac{\pi \overline{\lambda_{d}}}{8 \lambda^{2}}=\frac{\overline{\lambda_{d}}}{2 \pi \bar{r}^{2}}
$$

where $\overline{\lambda_{d}}$ is the average linear density of joints, $\lambda_{V}$ is the volume density of joints, $d$ is the diameter, and $\bar{r}$ is the average radius of joints.

According to formulas (4) to (7), the parameters of joint disc were calculated, as shown in Table 3.

The Monte Carlo method is a good tool for joint network modelling, which can approximately solve uncertain problems with a series of random numbers. In this paper, combined with the Monte Carlo method, the built-in language Fish provided by PFC is used to construct a threedimensional joint network model. The random numbers of joint disc parameters in accordance with corresponding probability distribution are generated in a $10 \mathrm{~m} \times 10 \mathrm{~m} \times 10 \mathrm{~m}$ cube space. Based on the OPEN GL technique, the joint network model in PFC is shown in Figure 6.

Then, the reliability of this model is tested by comparing the distribution of main joints in the effective area between the two-dimensional section of the model and the window of field survey. Figure 7 shows the joint distribution from the field survey and numerical model. The three-dimensional joint network model has a good statistical similarity with the real field distribution in attitude, scale, and density. The joints obtained from numerical models can well describe the real distribution characteristics of joints. 

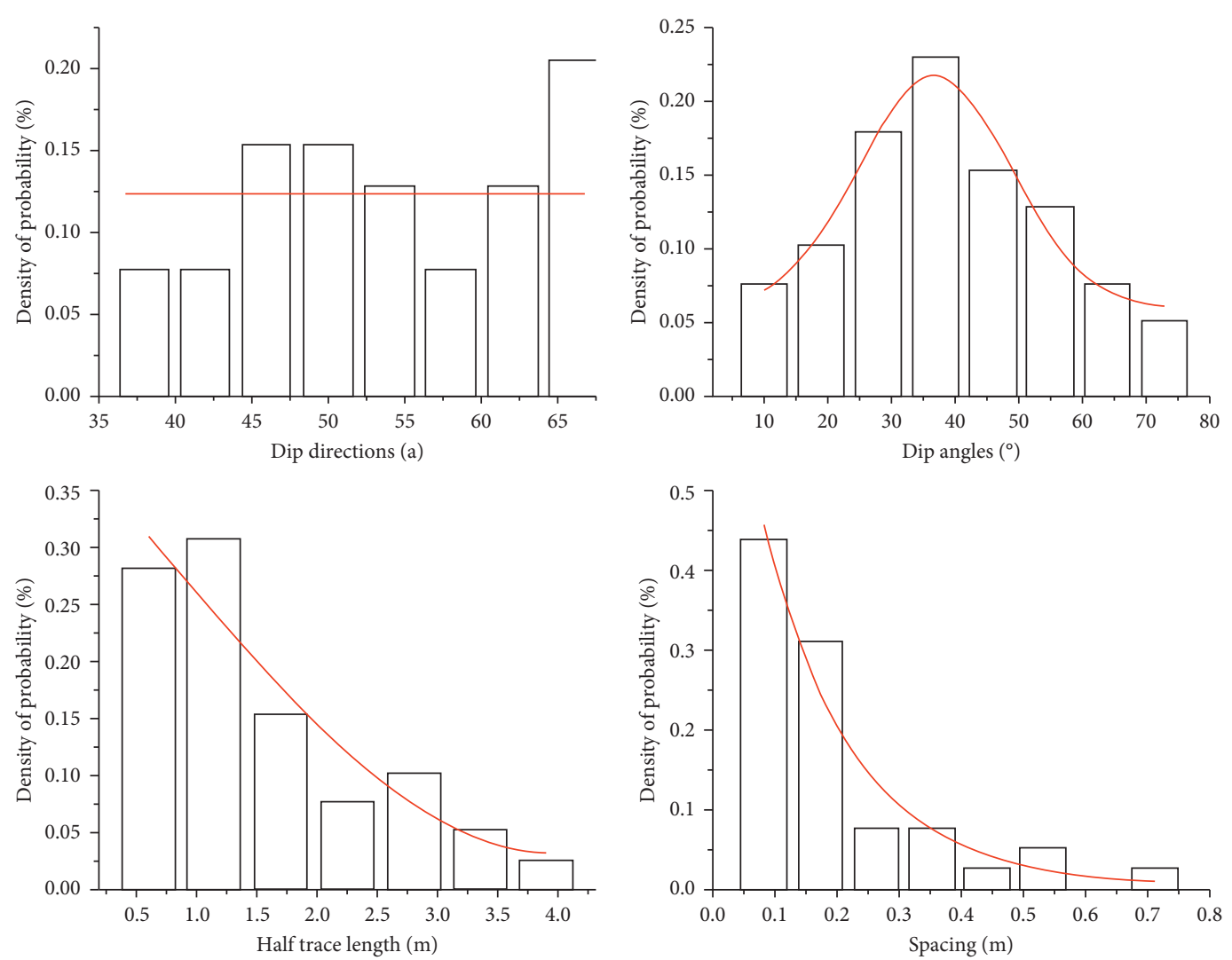

(a)
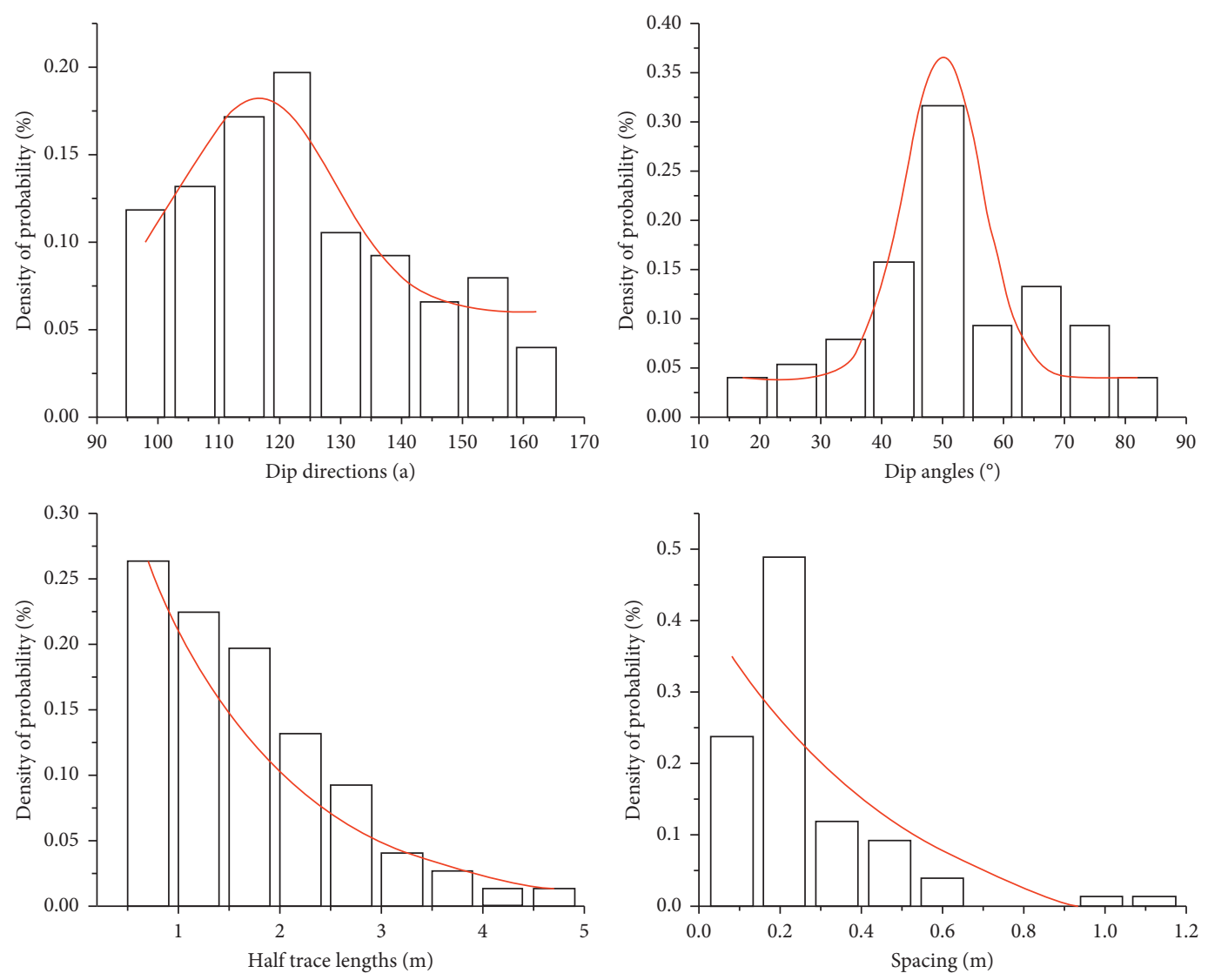

(b)

FIgUre 5: Continued. 

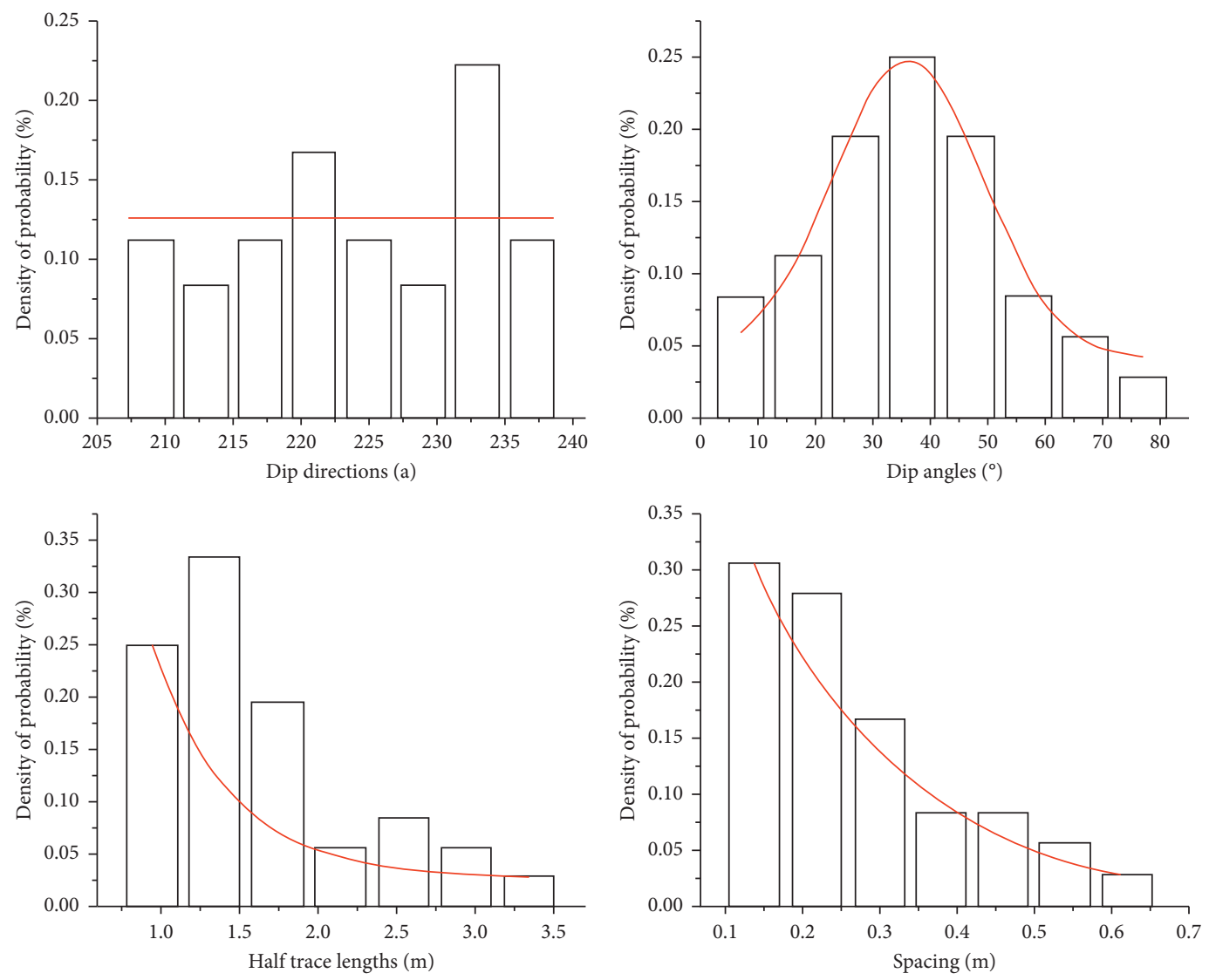

(c)
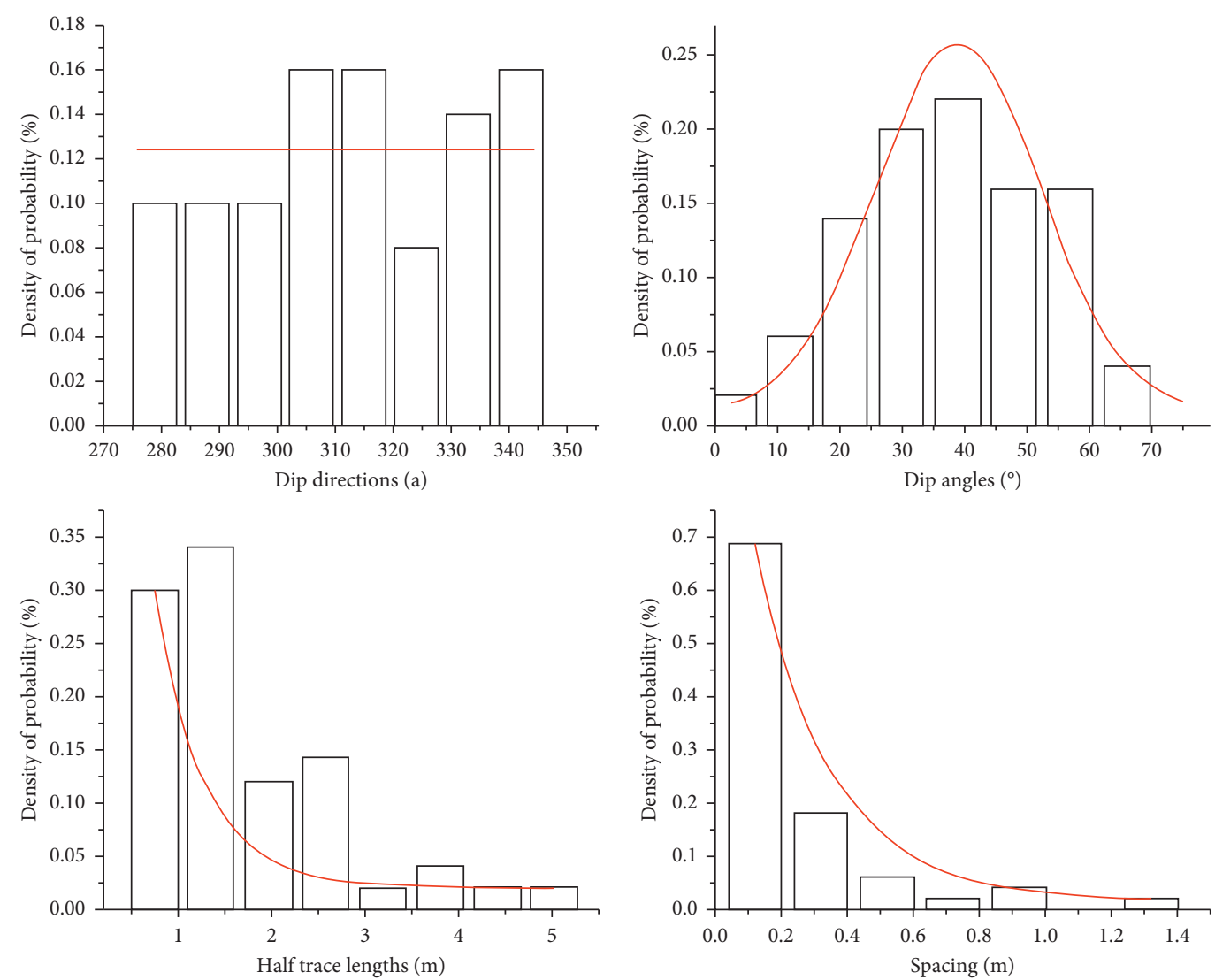

(d)

FIGURE 5: Histogram and probability density: (a) group A; (b) group B; (c) group C; (d) group D. 
TABle 2: The basic parameters and distribution for dominant orientations.

\begin{tabular}{|c|c|c|c|c|c|}
\hline \multirow{2}{*}{ Parameters } & & \multicolumn{4}{|c|}{ ID } \\
\hline & & A & $\mathrm{B}$ & $\mathrm{C}$ & $\mathrm{D}$ \\
\hline \multirow{3}{*}{ Dip direction $\left({ }^{\circ}\right)$} & Mean value & 57 & 131 & 249 & 318 \\
\hline & Standard deviation & 8.39 & 20.3 & 8.58 & 20.76 \\
\hline & Distribution law & $\mathrm{P}_{1}^{1}$ & $\mathrm{P}_{2}^{2}$ & $\mathrm{P}_{1}^{1}$ & $\mathrm{P}_{1}^{1}$ \\
\hline \multirow{3}{*}{ Dip angle $\left({ }^{\circ}\right)$} & Mean value & 44 & 54 & 41 & 42 \\
\hline & Standard deviation & 16.25 & 14.11 & 16.53 & 15.44 \\
\hline & Distribution law & $\mathrm{P}_{2}^{2}$ & $\mathrm{P}_{2}^{2}$ & $\mathrm{P}_{2}^{2}$ & $\mathrm{P}_{2}^{2}$ \\
\hline \multirow{3}{*}{ Half trace length (m) } & Mean value & 1.68 & 2.18 & 1.77 & 1.96 \\
\hline & Standard deviation & 0.87 & 0.85 & 0.63 & 1.01 \\
\hline & Distribution law & $\mathrm{P}_{3}{ }^{3}$ & $\mathrm{P} 3^{3}$ & $\mathrm{P}_{3}{ }^{3}$ & $\mathrm{P}_{3}^{3}$ \\
\hline \multirow{3}{*}{ Spacing $(\mathrm{m})$} & Mean value & 0.26 & 0.35 & 0.31 & 0.43 \\
\hline & Standard deviation & 0.11 & 0.18 & 0.14 & 0.29 \\
\hline & Distribution law & $\mathrm{P}_{3}^{3}$ & $\mathrm{P}_{3}{ }^{3}$ & $\mathrm{P}_{3}{ }^{3}$ & $\mathrm{P}_{3}{ }^{3}$ \\
\hline
\end{tabular}

${ }^{1} \mathrm{P}_{1}$ means uniform; ${ }^{2} \mathrm{P}_{2}$ means normal; ${ }^{3} \mathrm{P}_{3}$ means negative exponential.

TABLE 3: The parameters of joint disc.

\begin{tabular}{lccc}
\hline ID & Mean radius of disc $(\mathrm{m})$ & Linear density of joint $(\mathrm{crack} / \mathrm{m})$ & Volume density of joint $\left(\mathrm{crack} / \mathrm{m}^{3}\right)$ \\
\hline A & 2.14 & 3.81 & 0.1325 \\
B & 2.77 & 2.75 & 0.0612 \\
C & 2.25 & 3.22 & 0.1047 \\
D & 2.50 & 2.28 & 0.0657 \\
\hline
\end{tabular}

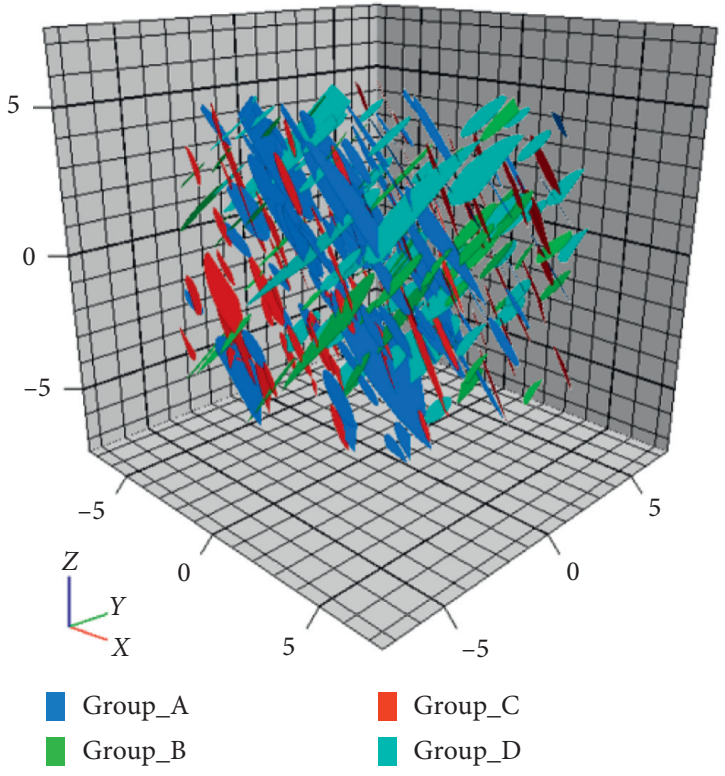

Figure 6: Stochastic joint network model.

\section{Calibration of the Microparameters}

The input microparameters in PFC software cannot be measured directly through conventional laboratory tests, which also have highly nonlinear relationships with the parameters such as Young's modulus, uniaxial compression strength, and Poisson's ratio in continuum numerical simulation. Therefore, parameter calibration is an essential part of simulation process in PFC to ensure that the microparameters can represent the macromechanical properties of rock well.
Before the calibration process, a series of conventional laboratory tests are carried out on Shuichang iron mine granite to obtain the mechanical parameters. The mechanical test equipment is shown in Figure 8. There are two sizes of experimental sample: $50 \mathrm{~mm}$ diameter and $100 \mathrm{~mm}$ height for compression tests and $50 \mathrm{~mm}$ diameter and $25 \mathrm{~mm}$ height for Brazilian tests, which are in good agreement with the sample sizes recommended by ISRM. Uniaxial compression tests and Brazilian tests are conducted at loading rates of $0.5-1.0 \mathrm{MPa} / \mathrm{s}$ and $0.1-0.3 \mathrm{MPa} / \mathrm{s}$, respectively. Triaxial compression tests were stress path control with a constant loading rate of $0.5 \mathrm{MPa} / \mathrm{s}$, and the confining pressures were $10,15,20$, and $25 \mathrm{MPa}$. In addition, direct shear tests were conducted on samples to obtain the joint parameters. The sample size is $10 \mathrm{~mm} \times 10 \mathrm{~mm} \times 10 \mathrm{~mm}$, with a constant horizontal shear rate of $0.01 \mathrm{~m} / \mathrm{s}$ under different normal stresses of 300,500 , and $700 \mathrm{kPa}$. The mechanical parameters of the granite obtained from experimental tests are given in Table 4.

4.1. Calibration of the FJM. As is known, calibration of the microparameters in PFC is a complicated process because it is impossible to describe the relationship between macroand microparameters with quantitative mathematical relation. The basic method to determine the microparameters is "trial-and-error." The specific method is as follows: by keeping other parameters constant, investigate the effect of one single parameter on simulation results, compare the macroparameters from laboratory tests results, and then repeat the above steps time and again until the parameter could be in good agreement with the observed macroscale response. 


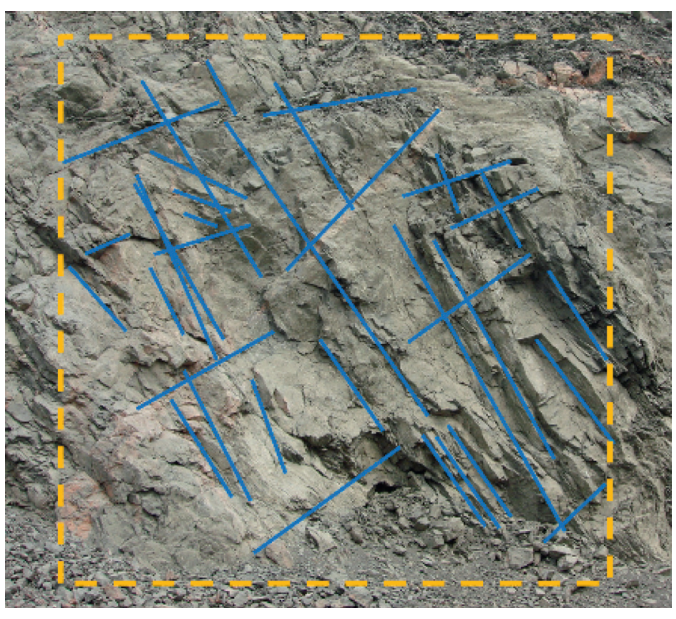

(a)

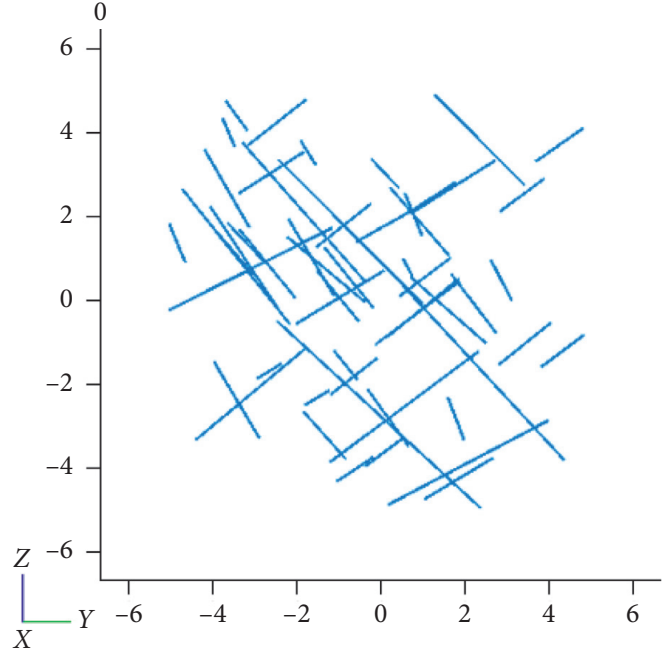

(b)

FIgURE 7: Comparison and verification of joints: (a) actual joints; (b) simulation joints.

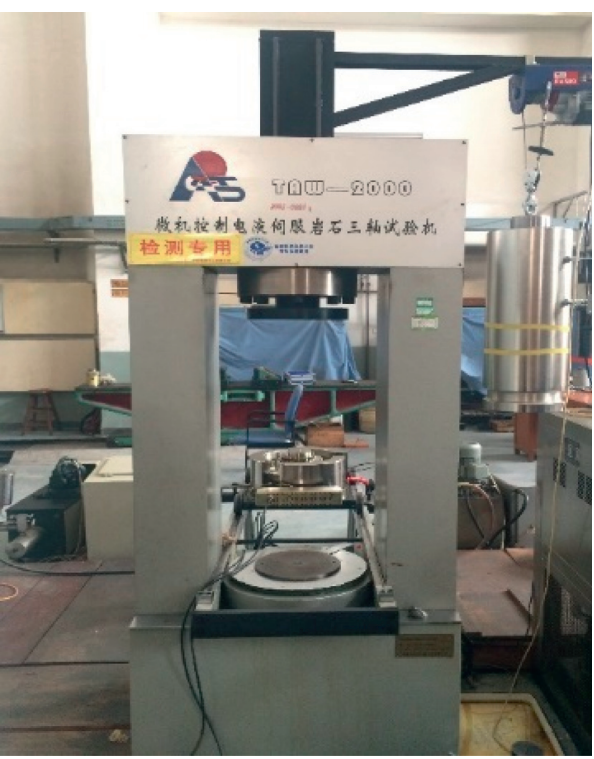

(a)

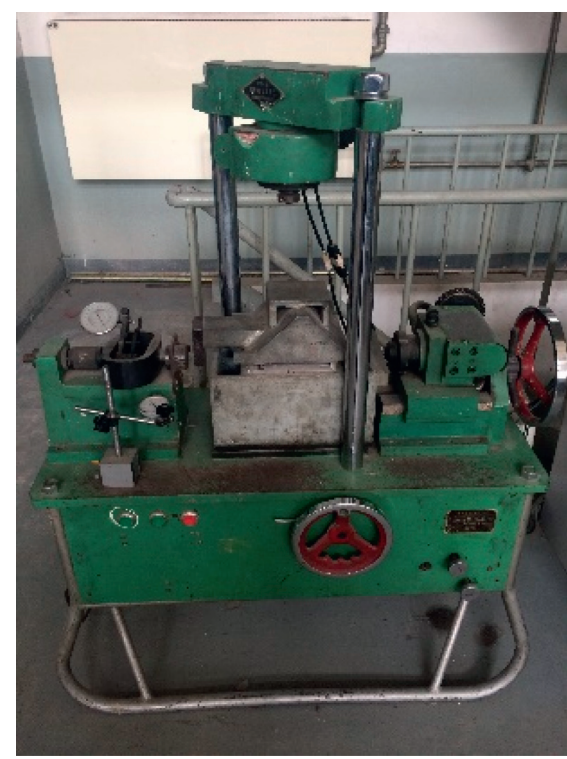

(b)

FIGURE 8: Mechanical test equipment: (a) uniaxial and triaxial compression test (TAW-2000); (b) direct shear test (XYJ-1).

TABLE 4: Mechanical properties of Shuichang open-pit iron mine granite from laboratory tests.

\begin{tabular}{|c|c|c|c|c|}
\hline Material & Property & Value & Property & Value \\
\hline \multirow{3}{*}{ Rock } & Density, $\rho\left(\mathrm{kg} \cdot \mathrm{m}^{-3}\right)$ & 2640 & Young's modulus, $E(\mathrm{GPa})$ & 55.23 \\
\hline & Poisson's ratio, $v$ & 0.183 & Uniaxial compression strength, $\sigma_{c}(\mathrm{MPa})$ & 125.71 \\
\hline & Cohesion, $c(\mathrm{MPa})$ & 12.35 & Internal friction angle, $\varphi\left({ }^{\circ}\right)$ & 41.51 \\
\hline \multirow{2}{*}{ Joint } & Tensile strength, $\sigma_{t}(\mathrm{MPa})$ & 6.65 & & \\
\hline & Cohesion, $c_{j}(\mathrm{kPa})$ & 27.83 & Internal friction angle, $\varphi_{j}\left({ }^{\circ}\right)$ & 21.06 \\
\hline
\end{tabular}

In this paper, the microparameters of the FJM in PFC, which affect the macromechanical properties of numerical sample, should be determined as shown in Table 5. Those microparameters are calibrated to match Young's modulus
$(E)$, Poisson's ratio $(\nu)$, uniaxial compression strength $\left(\sigma_{c}\right)$, tensile strength $\left(\sigma_{t}\right)$, cohesion $(c)$, and internal friction angle $(\varphi)$ of the model with respect to the rock sample. The tensile strength is matched based on the numerical direct tension 
TABLE 5: Microparameters of FJM.

\begin{tabular}{lcc}
\hline Microparameters & Description & Unit \\
\hline$d_{\min }$ & Minimum particle radius & mm \\
$d_{\text {max }} / d_{\text {min }}$ & Particle size ratio & - \\
$\bar{\lambda}$ & Radius multiplier & - \\
$N_{r}$ & Number of elements in radial direction & - \\
$N_{a}$ & Number of elements in circumferential direction & GPa \\
$E_{c}$ & Effective modulus of both particle and bond & - \\
$k_{\text {rat }}$ & Normal-to-shear stiffness ratio of both particle and bond & - \\
$\mu$ & Friction coefficient & MPa \\
$\sigma_{b}$ & Bond tensile strength & MPa \\
$c_{b}$ & Bond cohesion strength, & \\
$\Phi_{b}$ & Friction angle & \\
\hline
\end{tabular}

test, and the others are matched by using numerical uniaxial and triaxial compression tests. In addition, the other microparameters can be determined empirically by using the references.

Based on previous research, there are six microparameters that have significant effects on the numerical sample in the FJM, i.e., $E_{c}, k_{\text {rat }}, \mu, \sigma_{b}, c_{b}$, and $\Phi_{b}$. Therefore, a cylindrical sample model with a $50 \mathrm{~mm}$ diameter and a $100 \mathrm{~mm}$ height, which is in agreement with the rock sample size recommended by ISRM, is generated to simulate laboratory test (Figure 9). The sample model consisted of 14036 balls with radius varying from 1.00 to $1.66 \mathrm{~mm}$.

In the FJM, the calibration process is time-consuming due to no one-to-one correspondence existing between macroparameters and microparameters. For example, the UCS, Poisson's ratio, and cohesion occur in varying degrees of change with the change of microparameter $c_{b}$. To improve the efficiency and avoid adjusting parameters blindly, a $\mathrm{L}_{25}\left(5^{6}\right)$ orthogonal design test and range analysis were used to investigate the response law of macroparameters and microparameters. The orthogonal test table and calculated macroparameters are given in Appendix (Tables 12 and 13). The results of range analysis are shown in Table 6, where $R$ is the range value, to represent the influence of the microparameter on macroparameters, and a higher value indicates a higher ranking.

On the basis of aforementioned analytical results, a new improved trial-and-error method with high efficiency is used to calibrate the FJM. The final microparameters obtained are given in Table 7.

Then, the microparameters were verified by using the numerical test. Figure 10 illustrates the stress-strain curves of uniaxial compressive test and failure modes from experimental result and numerical result. The stress-strain curves, both before and after the peak, are consistent with those of the experiment, and the failure patterns from the experiment and numerical test are quite similar.

The comparison of basic mechanical parameters between the experimental and numerical results is shown in Table 8. The errors of Poisson's ratio, uniaxial compression strength, and tensile strength are $3.83 \%, 2.31 \%$, and $3.16 \%$, respectively. Young's modulus and internal friction angle are just $0.94 \%$ and $0.53 \%$ larger than the experimental results, respectively. The value of cohesion from simulation yields the largest errors, which is $9.64 \%$ higher than the experimental value, but that is still less than $10 \%$. Obviously, the properties obtained from the numerical tests with calibrated parameters are in good agreement with those from experiment.

4.2. Calibration of the SJM. The macroparameters of the SJM are usually determined by simulating the direct shear test sample of rock joint. In this paper, an unbonded SJM is selected, that is, the parameter "sj_state" is set to 0 . As in the case of FJM calibration, a model with the same size as the experimental sample was generated in cube shear box, and a suitable set of microparameters of SJM was obtained based upon numerical direct shear tests matching the laboratory test response of the rock, as shown in Table 9.

The shear stress-shear displacement curves under different normal stresses from experimental and numerical direct shear tests are shown in Figure 11. The cohesion and internal friction angle of SJM can be calculated by using strength envelope according to those curves. The values of these two parameters are $30.58 \mathrm{kPa}$ and $20.2^{\circ}$, which are $9.88 \%$ higher and $4.08 \%$ lower than the experimental value, respectively. Clearly, the calibration parameters can represent the macromechanical properties of rock mass well.

4.3. Scale Effect. Due to the randomness in the distribution of joints, scale effect can substantially influence the rock strength, namely, the strength of a region decreases with increase in region size up to the point at which a representative size is reached. Compared with the engineering rock mass, the laboratory samples are usually small and do not contain systematic joints which affect the rock strength. For this reason, the microparameters of engineering rock mass in the SRM model should be considered for the potential impacts of joints and should be calibrated to match a strength that reflects the size of a typical rock mass, instead of a core sample. Hence, a concept named "representative elementary volume (REV)" is introduced, which is the minimum size with which the rock mechanical properties can be treated as equivalent continuous [51, 52].

In order to investigate the scale effect and REV size of rock mass, seven SRM models with different sizes were established to conduct numerical uniaxial compression tests. These cubical models with side lengths of $1,2,6,10,14,16$, 


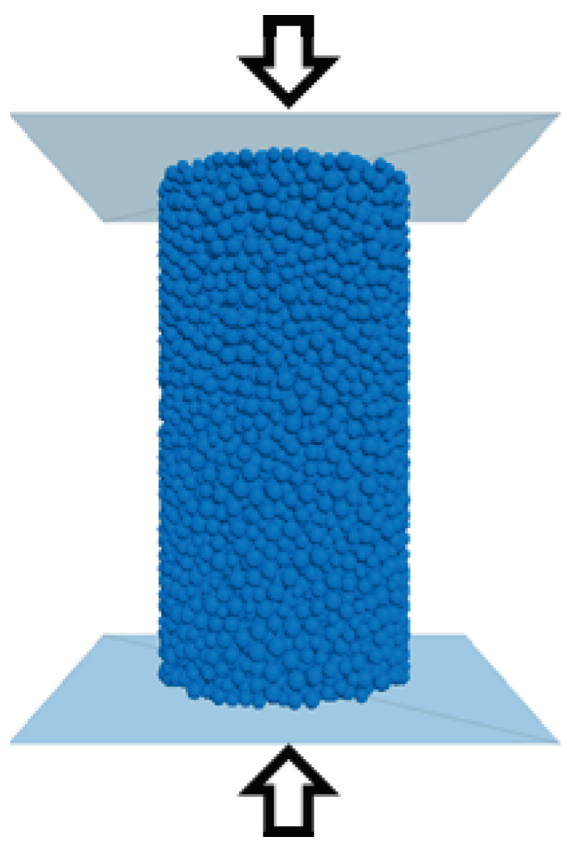

(a)

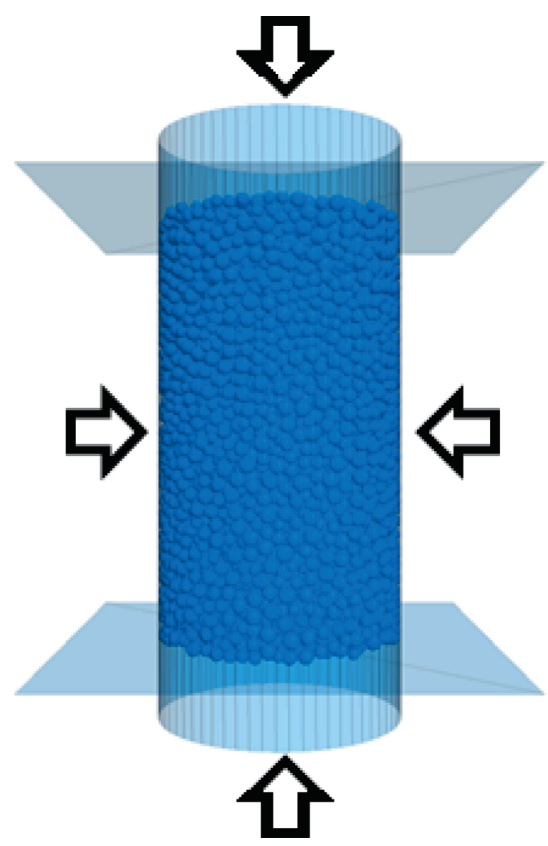

(b)

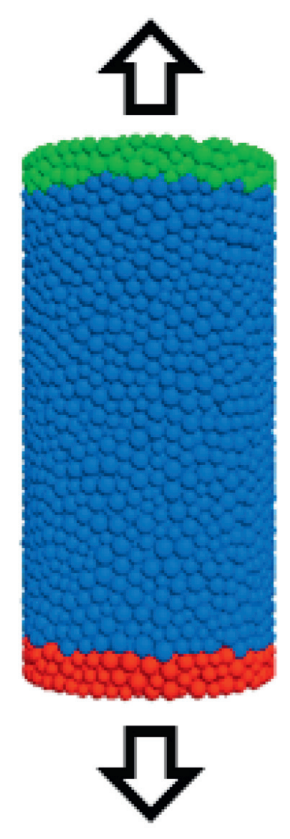

(c)

FIgURE 9: Numerical model for rock mechanic test: (a) uniaxial compression test; (b) triaxial compression test; (c) direct tension test.

TABLE 6: Results of range analysis.

\begin{tabular}{|c|c|c|c|c|c|c|c|}
\hline \multirow{2}{*}{ Macroparameters } & \multirow{2}{*}{ Range value and ranking } & \multicolumn{6}{|c|}{ Microparameters } \\
\hline & & $E_{c}$ & $k_{\text {rat }}$ & $\mu$ & $\sigma_{b}$ & $c_{b}$ & $\Phi_{b}$ \\
\hline \multirow{2}{*}{$\sigma_{c}$} & $R$ & 15.882 & 18.656 & 21.266 & 23.886 & 107.58 & 13.212 \\
\hline & Ranking & \multicolumn{6}{|c|}{$c_{b}>\sigma_{b}>\mu>k_{r a t}>E_{c}>\Phi_{b}$} \\
\hline \multirow{2}{*}{ E } & $R^{\mathcal{O}}$ & 56.56 & 18.296 & 16.4 & 8.638 & 9.784 & 17.104 \\
\hline & Ranking & \multicolumn{6}{|c|}{$E_{c}>k_{\text {rat }}>\Phi_{b}>\mu>c_{b}>\sigma_{b}$} \\
\hline$v$ & $\begin{array}{c}R \\
\text { Ranking }\end{array}$ & \multicolumn{6}{|c|}{$k_{\text {rat }}>\sigma_{b}>c_{b}>\mu>E_{c}>\Phi_{b}$} \\
\hline$\sigma_{t}$ & $\begin{array}{c}R \\
\text { Ranking }\end{array}$ & 0.742 & 1.3158 & $\begin{array}{c}0.9906 \\
\sigma_{b}>k_{\text {rat }}>\end{array}$ & $\begin{array}{r}5.598 \\
E_{c}>\Phi_{b}\end{array}$ & 0.8236 & 0.464 \\
\hline$c$ & $\begin{array}{c}R \\
\text { Ranking }\end{array}$ & \multicolumn{6}{|c|}{$c_{b}>k_{r a t}>\mu>E_{c}>\sigma_{b}>\Phi_{b}$} \\
\hline$\varphi$ & $\begin{array}{c}R \\
\text { Ranking }\end{array}$ & 2.572 & 4.53 & $\begin{array}{c}8.71 \\
\Phi_{b}>\mu>c\end{array}$ & $\begin{array}{r}3.17 \\
\sigma_{b}>E_{c}\end{array}$ & 5.66 & 10.124 \\
\hline
\end{tabular}

TABLE 7: Microparameters of the FJM after calibration.

\begin{tabular}{lccccccccccc}
\hline Microparameter & $d_{\min }(\mathrm{mm})$ & $d_{\max } / d_{\min }$ & $\bar{\lambda}$ & $N_{r}$ & $N_{a}$ & $E_{c}(\mathrm{GPa})$ & $k_{\text {rat }}$ & $\mu$ & $\sigma_{b}(\mathrm{MPa})$ & $c_{b}(\mathrm{MPa})$ & $\Phi_{b}\left({ }^{\circ}\right)$ \\
\hline Value & 1.0 & 1.66 & 1 & 1 & 3 & 76 & 1.8 & 0.4 & 14 & 135 & 5 \\
\hline
\end{tabular}

and $20 \mathrm{~m}$, respectively, are shown in Figure 12. Moreover, the geometric centers of these models were fixed to make calculated results comparable. The calibrated microparameters in Tables 7 and 9 were used to represent macromechanical properties of rock.

Figure 13 shows the calculated stress-strain curve of multiscale models. As expected, the strength parameters decrease with the increase of model size, showing obvious scale effect.

The results are presented in Figure 14. Uniaxial compression strength decreases approximately linearly with the increase of size and begins to fluctuate around a stable value of $30 \mathrm{MPa}$ after the size is larger than $16 \mathrm{~m}$. The same goes for Young's modulus; the values are close to $23 \mathrm{GPa}$ when the size increases from $14 \mathrm{~m}$ to $20 \mathrm{~m}$. Therefore, it can be concluded that the REV size is $16 \mathrm{~m} \times 16 \mathrm{~m} \times 16 \mathrm{~m}$. In other words, the minimum size of a rock sample representing the property of engineering rock in Shuichang open-pit iron mine is $16 \mathrm{~m} \times 16 \mathrm{~m} \times 16 \mathrm{~m}$.

4.4. Final Calibration. In this paper, combined with the results from the laboratory tests, the mechanical parameters of engineering rock mass were estimated by using RocLab software based on the Hoek-Brown (H-B) method. 


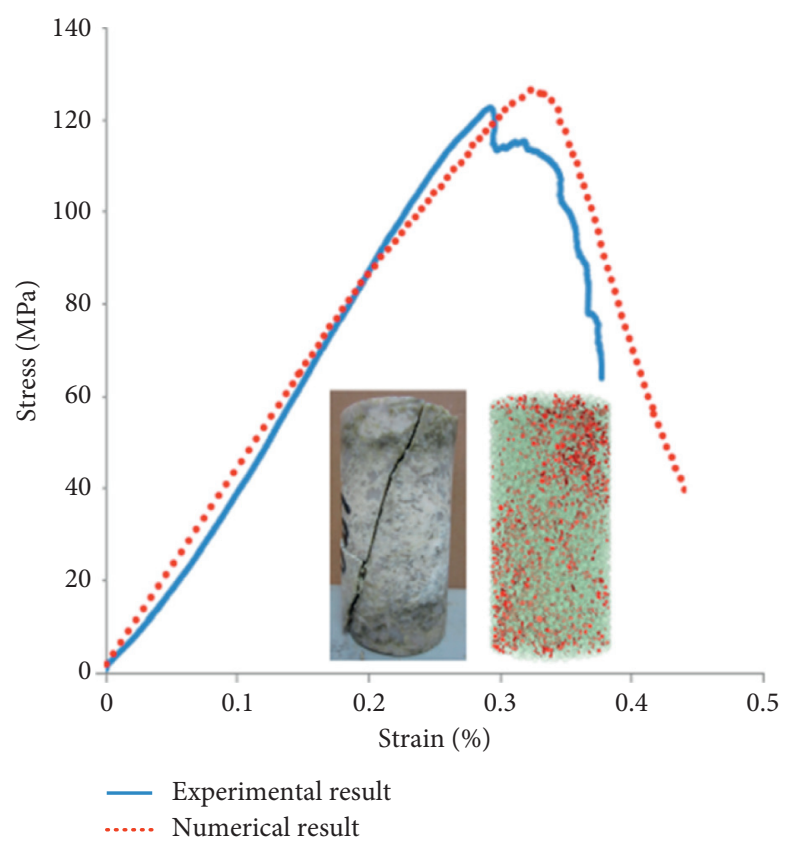

Figure 10: Comparison of uniaxial compressive test from experimental and numerical results.

TABLE 8: Comparison of mechanical parameters between experimental and numerical tests.

\begin{tabular}{lcccccc}
\hline Mechanical property & $E(\mathrm{GPa})$ & $\nu$ & $\sigma_{\mathrm{c}}(\mathrm{MPa})$ & $c(\mathrm{MPa})$ & $\varphi\left(^{\circ}\right)$ & $\sigma_{t}(\mathrm{MPa})$ \\
\hline Experimental result & 55.23 & 0.183 & 125.71 & 12.35 & 41.51 & 6.65 \\
Numerical result & 55.75 & 0.190 & 128.61 & 13.54 & 41.73 & 6.86 \\
Error (\%) & 0.94 & 3.83 & 2.31 & 9.64 & 0.53 & 3.16 \\
\hline
\end{tabular}

TABLE 9: Microparameters of the SJM after calibration.

\begin{tabular}{|c|c|c|}
\hline Microparameter & Description & Value \\
\hline$s j_{-} k_{n}\left(\mathrm{~N} \cdot \mathrm{m}^{-1}\right)$ & Normal stiffness & $2.5 \times 10^{7}$ \\
\hline$s j \_k_{s}\left(\mathrm{~N} \cdot \mathrm{m}^{-1}\right)$ & Shear stiffness & $2.5 \times 10^{7}$ \\
\hline sj_fric & Friction coefficient & 0.5 \\
\hline$s j-d a\left({ }^{\circ}\right)$ & Dilation angle & 5 \\
\hline$s j \_s t a t e$ & Joint bond state & 0 \\
\hline$s j \_t e n(\mathrm{MPa})$ & Bonded tensile strength & 0 \\
\hline sj_bcoh $(\mathrm{MPa})$ & Bonded cohesion & 0 \\
\hline$s j \_b f a\left(^{\circ}\right)$ & Bonded friction angle & 0 \\
\hline
\end{tabular}

The failure envelope curve of engineering rock mass in Shuichang open-pit iron mine is shown in Figures 15 and 16.

Subsequently, a series of sample models were established based on the REV size to conduct numerical tests. Making use of the method mentioned in Section 4.1, the microparameters of SRM were calibrated to match the mechanical parameters of engineering rock mass. The final microparameters of engineering rock mass in SRM are presented in Table 10.

The comparison of basic mechanical parameters between the Hoek-Brown method and numerical results is shown in Table 11. While the errors of the result are limited within $10 \%$, it is considered to be a suitable set of microparameters to represent the macromechanical properties of engineering rock mass well.

\section{Engineering Case}

5.1. Engineering Background. The field joint survey was carried out on the north side of the open-pit mine slope, No. II mining area of Shuichang iron mine. Rock mass quality in this area is declined due to the well-developed discontinuous nature of rock such as fault and joint, causing local instability of slope. Records show multiple rock fall and landslips occurred in this area, especially at elevation $44 \mathrm{~m}-116 \mathrm{~m}$. A 3D numerical model is developed using the PFC software in order to investigate the micromechanism of failure of jointed rock slope during excavation process.

5.2. Construction of Jointed Rock Model. The model takes the direction of perpendicular to the stope as the $x$-axis, extension direction of slope is $y$-axis, and vertical direction is $z$ axis. The lengths along the axis of $x, y$, and $z$ are $140 \mathrm{~m}, 20 \mathrm{~m}$, and $90 \mathrm{~m}$, respectively. For obtaining reliable simulation results, the ratio of smallest characteristic length for the model to the median particle radius should be $50-100$ [33, 34, 53-55]. Considering the computational efficiency and accuracy, the minimum particle radius and particle size ratio are set as $0.3 \mathrm{~m}$ and 1.66 , respectively. The four groups' dominant orientations of joints obtained in section 3.1 were added into the model successively. The model before excavation is composed of 81886 particles and 54219 cracks, as shown in Figure 17. The height and slope angle of bench in 


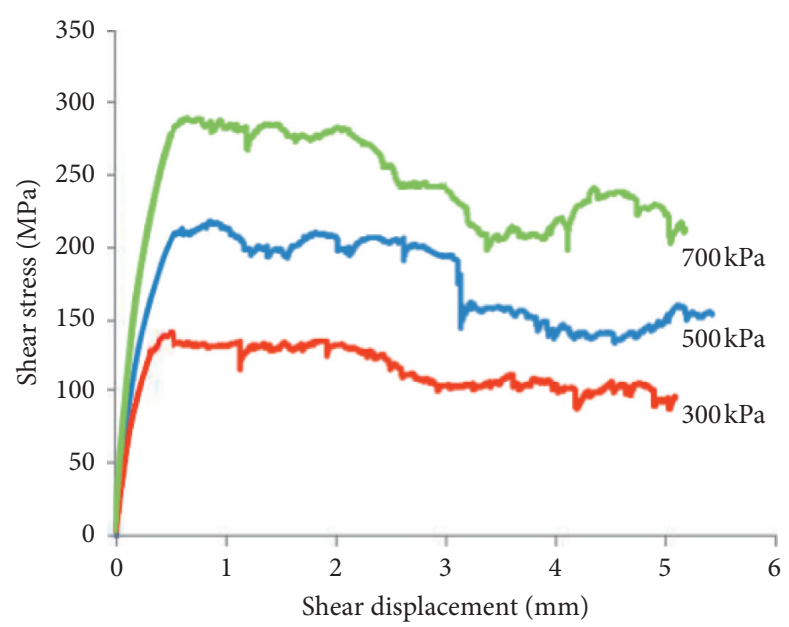

(a)

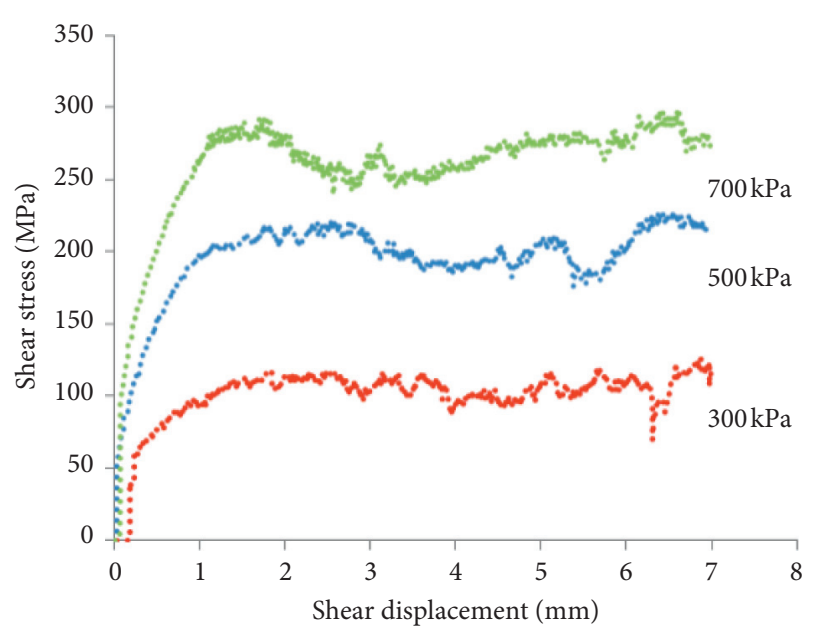

(b)

FIgURE 11: Shear stress-shear displacement curves under different normal stresses: (a) numerical results; (b) experimental results.

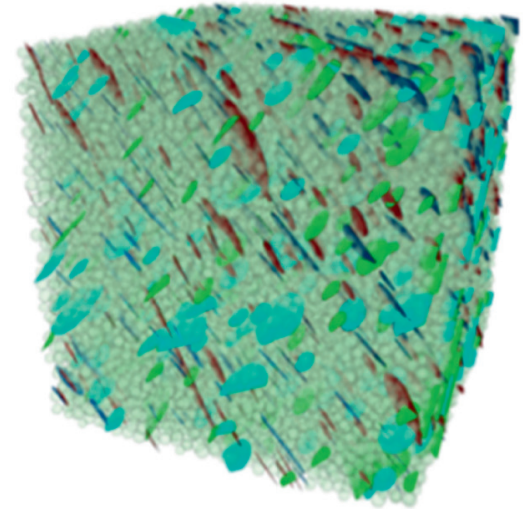

$20 \mathrm{~m}$

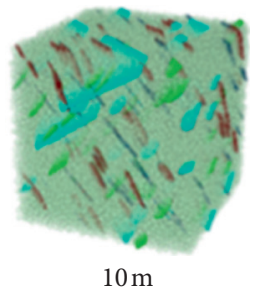

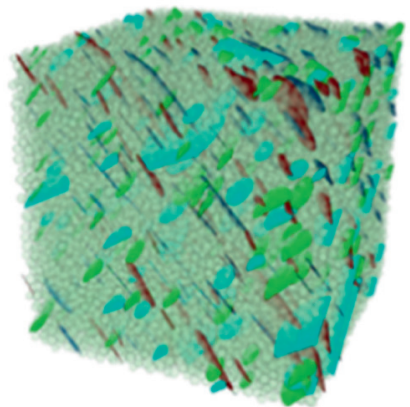

$16 \mathrm{~m}$

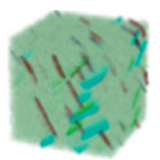

$6 \mathrm{~m}$

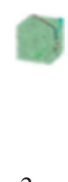

$2 \mathrm{~m}$

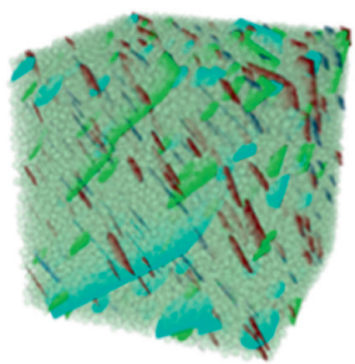

$14 \mathrm{~m}$
$1 \mathrm{~m}$

FIGURE 12: Multiscale SRM models.

this model are $15 \mathrm{~m}$ and $65^{\circ}$, respectively, which are entirely consistent with the facts. In what concerns the model boundary conditions, the horizontal displacements in the model's vertical boundaries were fixed, along with all of the displacements in the lower boundary. The slope surface and higher boundary were free. Because the main rock of this area is granite, the strength parameters of rock mass and joint are selected according to Table 10.

5.3. Micromechanical Analysis of Slope Failure. In PFC, particles are rigid spherical bodies with bonded contacts representing intact rock. And those contacts will be broken in shear mode or tension mode when external force exceeds the bonding strength. Therefore, the number, mode, and propagation of crack can be used to analyze the failure evolution. In this paper, the model is excavated by four steps, one bench at a time. Subsequently, the failure mechanism during the excavation process was investigated from micromechanical viewpoint based on PFC software.

Figure 18 illustrates the relationship between crack number and timestep. It should be noticed that generation of cracks is concentrated in a short time (about 4000 timestep) after excavation, which indicates that excavation may cause instantaneous failure of slope. Moreover, with the progress of excavation, the number of cracks is increasing to a total of 


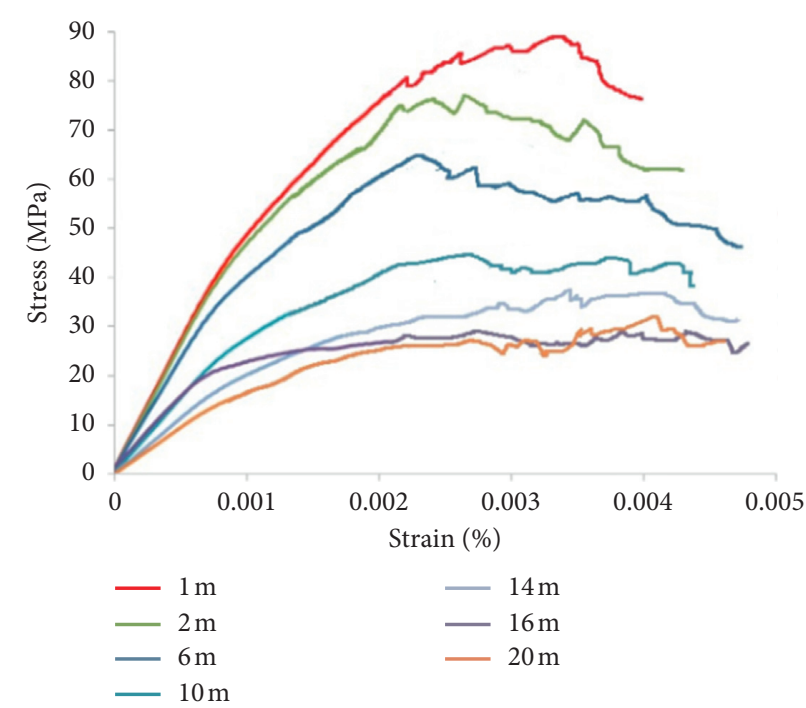

FIGURE 13: Stress-strain curve of the multiscale SRM model.

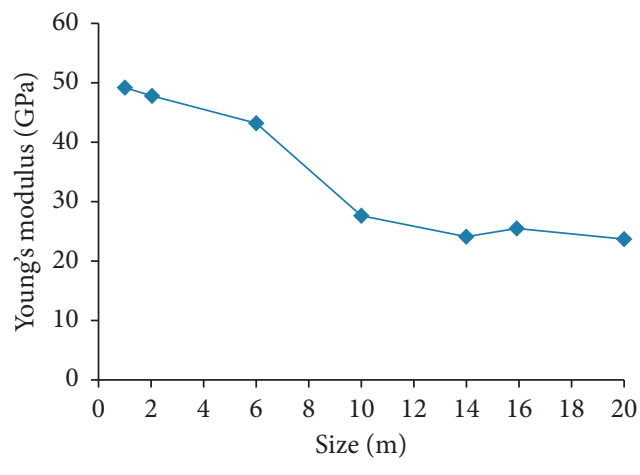

$\neg$ Young's modulus

(a)

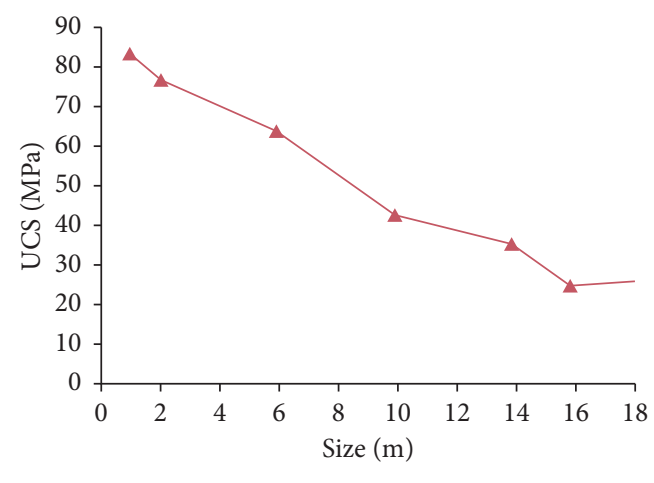

$\rightarrow$ UCS

FIgURE 14: Scale effect analysis of different strength parameters: (a) Young's modulus; (b) UCS.

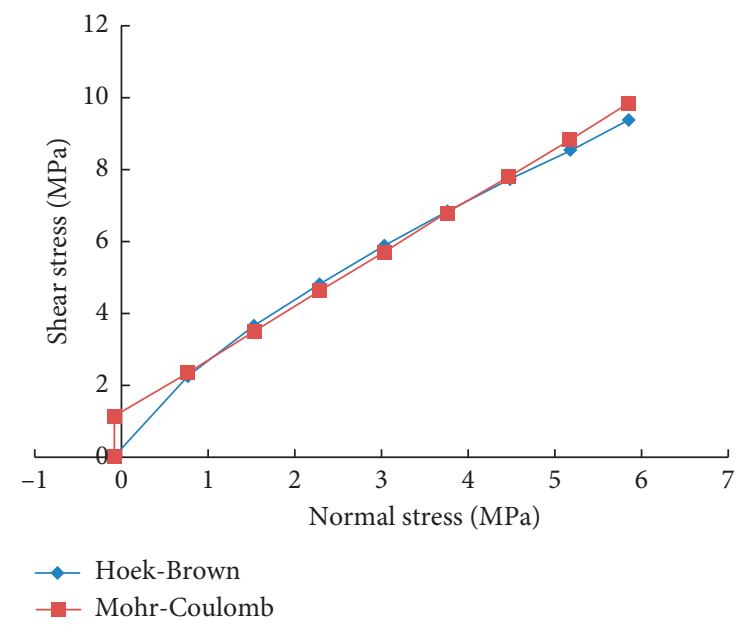

Figure 15: Normal stress-shear stress curve.

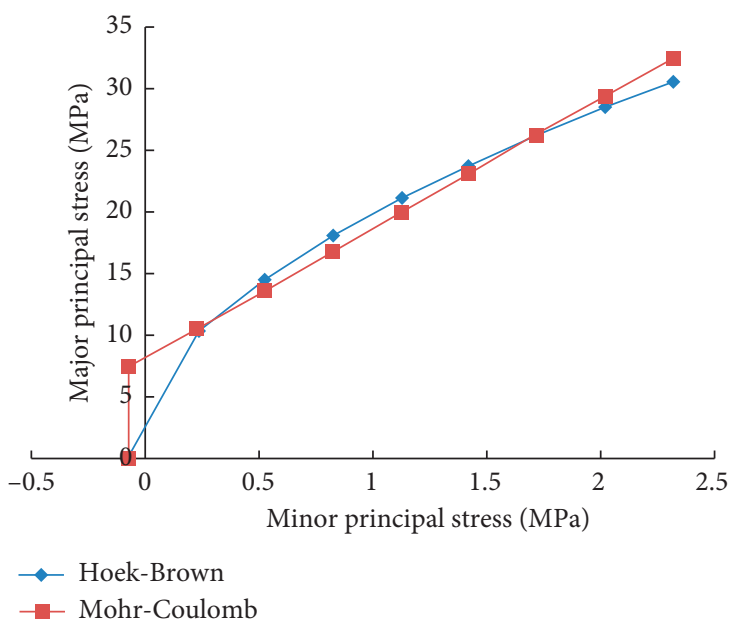

FIGURE 16: Minor-major principal stress curve. 
TABLE 10: The microparameters of engineering rock mass in the SRM model.

\begin{tabular}{lcccccccccc}
\hline \multirow{2}{*}{ Microparameter } & \multicolumn{9}{c}{ FJM } & \multicolumn{4}{c}{ SJM } \\
& $E_{c}(\mathrm{GPa})$ & $k_{\text {rat }}$ & $\mu$ & $\sigma_{b}(\mathrm{MPa})$ & $c_{b}(\mathrm{MPa})$ & $\Phi_{b}\left({ }^{\circ}\right)$ & $s j \_k_{n}\left(\mathrm{~N} \cdot \mathrm{m}^{-1}\right)$ & $s j \_k_{s}\left(\mathrm{~N} \cdot \mathrm{m}^{-1}\right)$ & $s j \_$fric & $s j \_d a\left(^{\circ}\right)$ \\
\hline Value & 18 & 1.6 & 0.5 & 0.18 & 0.84 & 6 & $2.5 \times 10^{7}$ & $2.5 \times 10^{7}$ & 0.5 & 5 \\
\hline
\end{tabular}

TABle 11: Comparison of mechanical parameters between the H-B method and numerical tests.

\begin{tabular}{llllll}
\hline Mechanical property & $E^{\prime}(\mathrm{GPa})$ & $\sigma_{c}^{\prime}(\mathrm{MPa})$ & $c^{\prime}(\mathrm{MPa})$ & $\varphi^{\prime}\left({ }^{\circ}\right)$ & 41.73 \\
H-B method & 14.09 & 9.153 & 3.513 & $\sigma_{t}^{\prime}(\mathrm{MPa})$ \\
Numerical result & 13.15 & 10.041 & 3.814 & 43.36 & 0.154 \\
Error (\%) & 6.671 & 9.702 & 8.568 & 3.906 & 0.151 \\
\hline
\end{tabular}
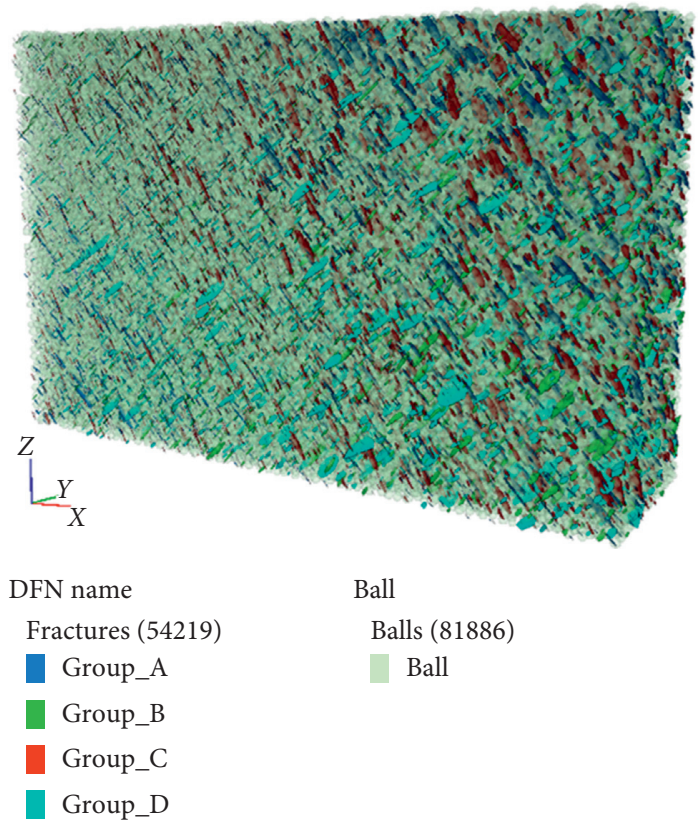

FIgURE 17: Jointed rock slope model before excavation of Shuichang open-pit iron mine.

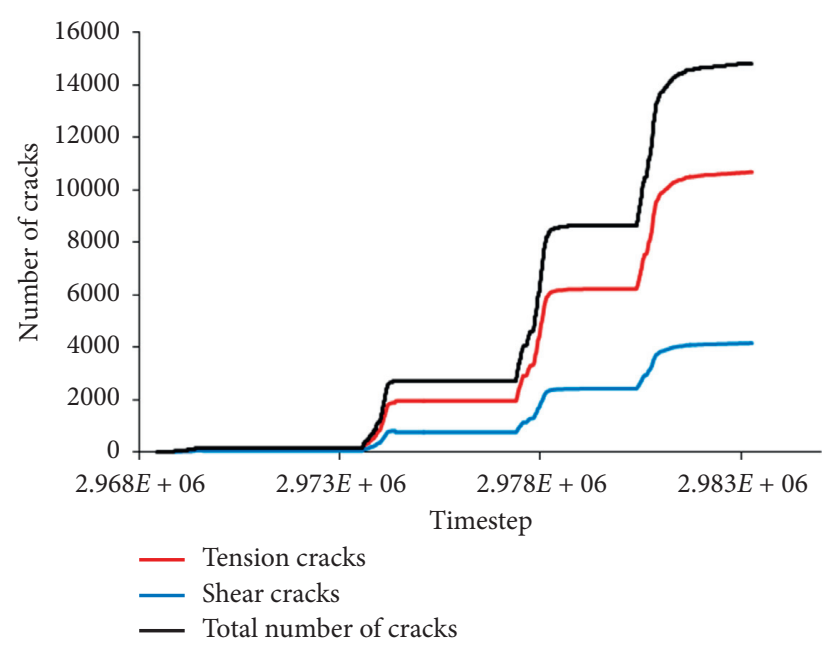

FIgURE 18: The number of microcracks during excavation. 


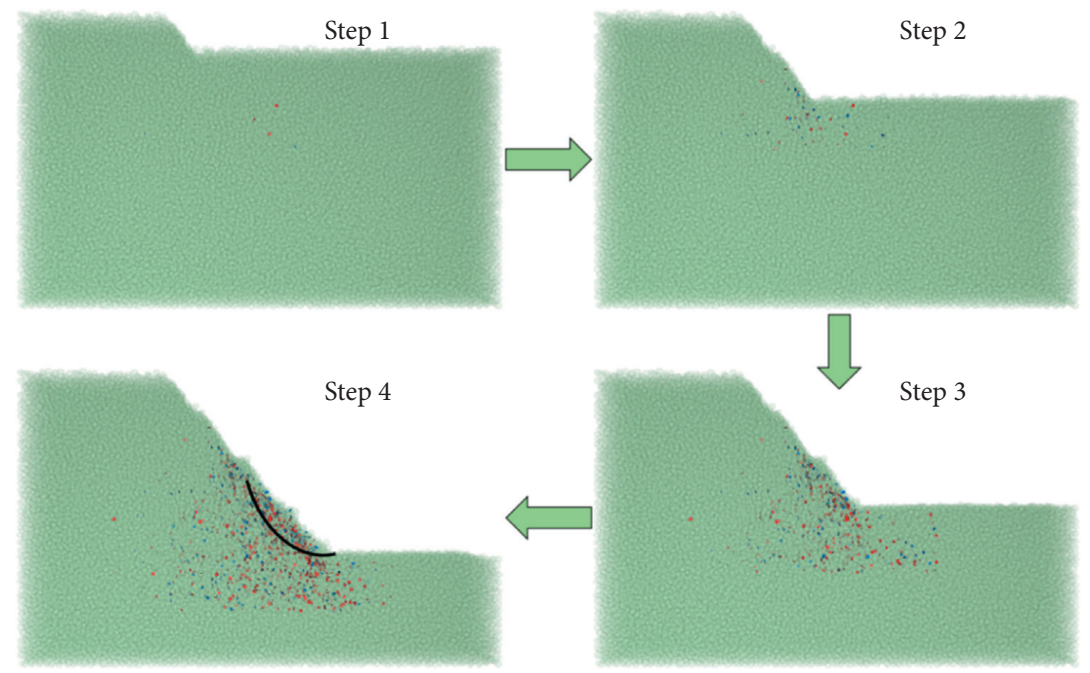

FIGURE 19: Evolutionary process of microcrack.

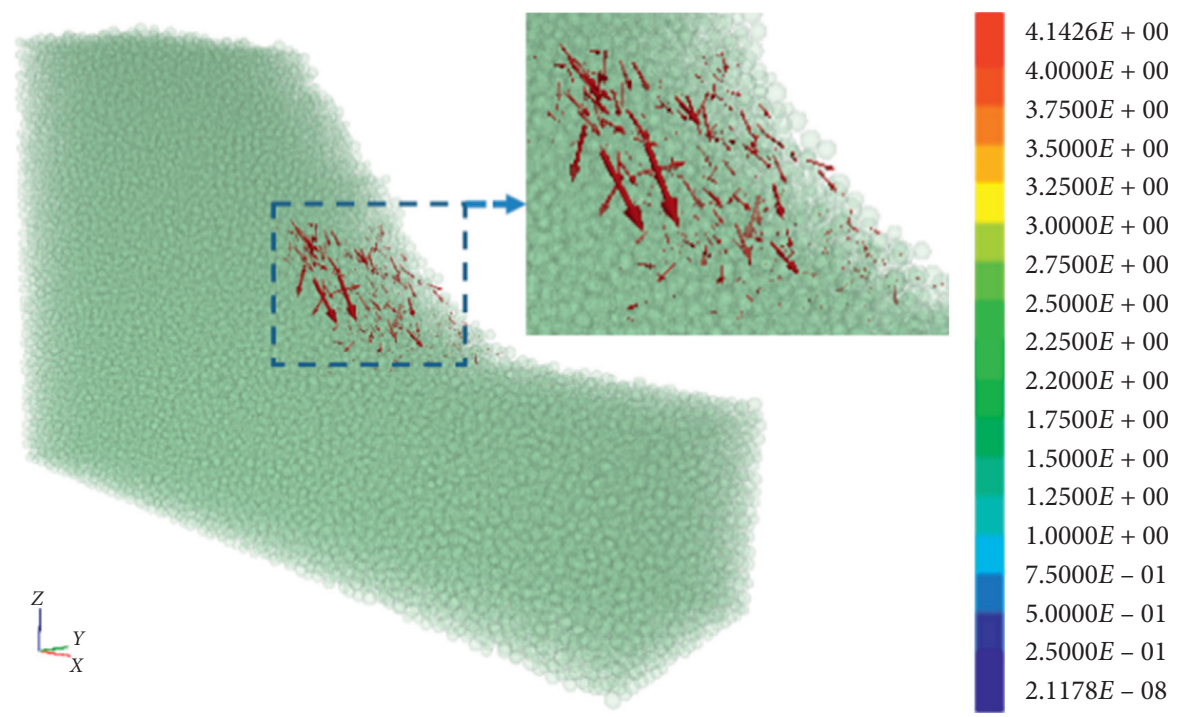

Figure 20: Velocity vector diagram.

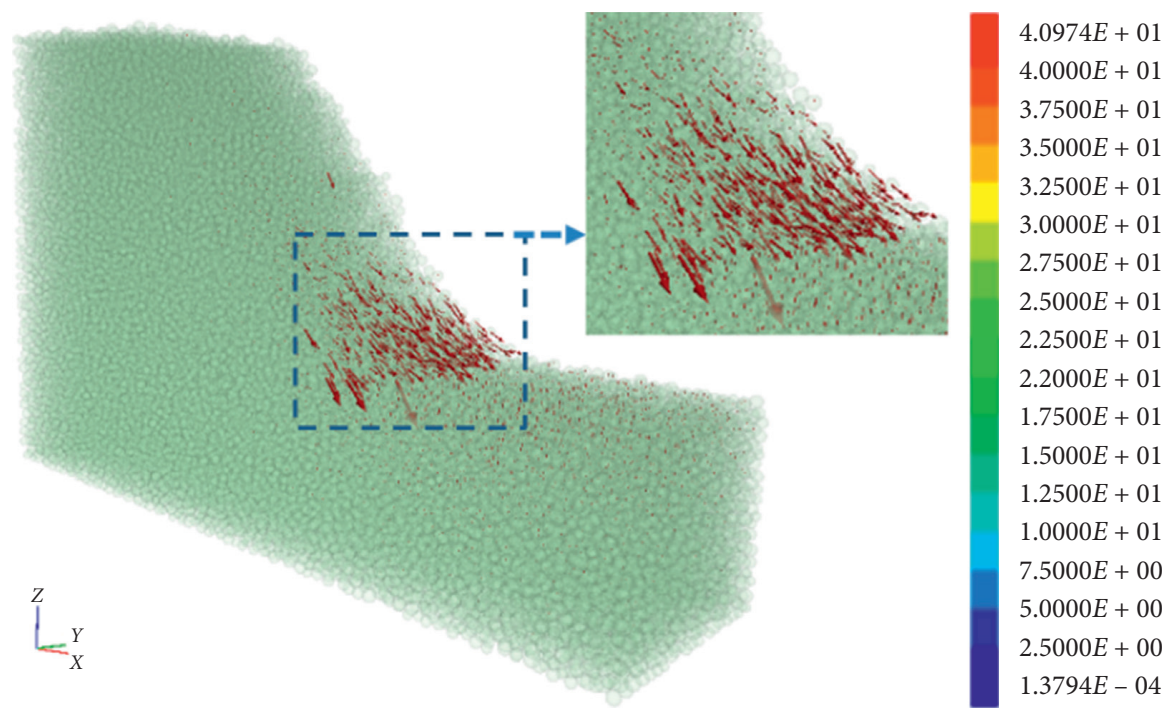

FIgURE 21: Displacement vector diagram. 


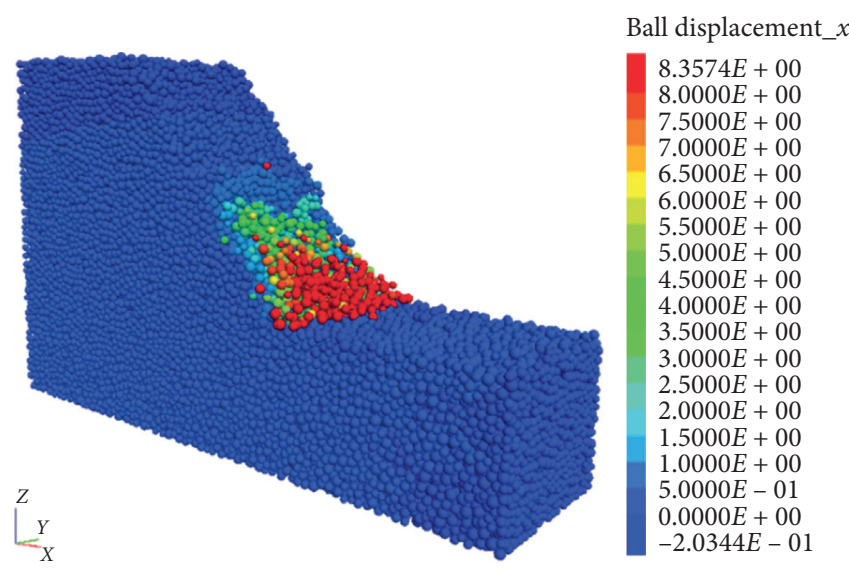

(a)

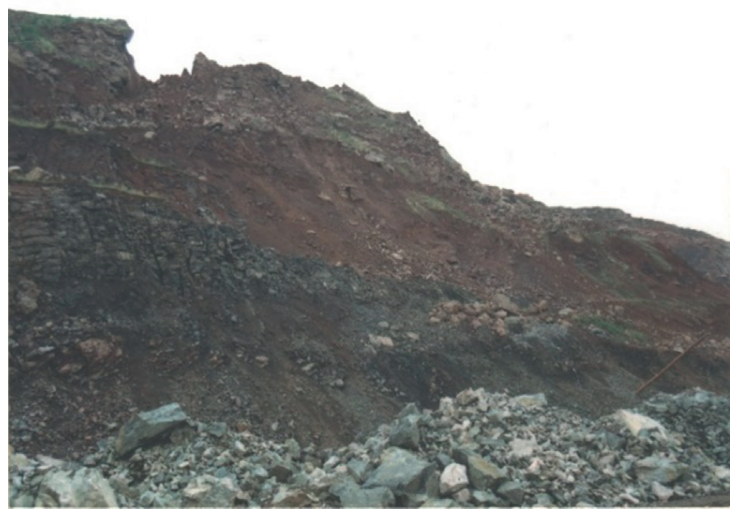

(b)

FIGURE 22: Failure mode of the slope: (a) simulation result; (b) current situation.

14800 , and the number of tensile cracks is much more than that of shear cracks at any timestep. It can be inferred that the failure is essentially caused by the dominated tensile microcracks.

Figure 19 shows the evolutionary process of microcracks during excavation, where the tensile crack and shear crack are shown in red and blue, respectively. In the first two steps, a small number of cracks appeared around the toe of the slope. From the third step, cracks begin to increase sharply in number and expand constantly inside the slope. At the end of the excavation process, the distribution of cracks reaches a depth of about $50 \mathrm{~mm}$, and the tensile crack almost propagates through from the middle of the third bench to the toe of the fourth bench, forming a macro fracture zone.

Diagrams of velocity vector (Figure 20) and displacement vector (Figure 21) clearly show the distribution of potential unstable rock mass when the slope is unstable. The distribution is the same as that of microcrack. The velocity and displacement around the third and top of the fourth bench are larger than other regions.

Figure 22(a) shows the horizontal displacement of particles at the end of the simulation. Particles with large displacement are mainly concentrated in the middle and lower part of the slope, some of which have been separated from parent rocks and form a rock fall. And due to the cross cuttings of joints, the main failure mode of slope is wedge failure, being relatively complete in the upper and seriously damaged in the lower of the whole slope, which is consistent with the actual situation, as shown in Figure 22(b).

\section{Conclusions}

In this paper, the SRM model was established in PFC software to represent the mechanical properties of rock mass from Shuichang open-pit iron mine. Based on the prepared model, the failure mechanism during excavation process was investigated from the micromechanical viewpoint. The conclusions of this study are as follows:

(1) statistical analysis method can act as a useful tool to group the dominant orientations of joints and determine the geometric parameters such as dip angle, size, and trace length. The joint distributions of Shuichang slope were obtained by the field survey and quantitatively described in the numerical model.

(2) The effects of different microparameters on macromechanical properties of rock are different. Through the orthogonal experiment and variance analysis, the calibration and optimization of the parameters were accomplished. The mechanical properties including stress-strain curve and failure pattern from numerical results were verified with those from experimental results.

(3) The existence of joints results in scale effect and anisotropic behavior of rock mass, and these properties tend to gradually weaken with the increasing rock block size. By carrying out numerical tests on multiscale SRM models, the representative elementary volume (REV) in the selected research area was obtained with the size $16 \mathrm{~m} \times 16 \mathrm{~m} \times 16 \mathrm{~m}$. Then, the microparameters of the SRM model were calibrated to match the mechanical parameters of the engineering rock mass.

(4) SRM is an effective method to analyze the failure evolution of jointed rock slope. The failure of the slope was dominated by the tensile microcracks between bonded particles. The microcracks primarily occurred at the bottom of the slope and gradually developed upwards. In addition, microcracks were mainly distributed on the shallow part of the slope. After excavation, the wedge occurred in the middle and bottom part of the slope (Appendix) (Tables 12 and 13). 


\section{Appendix}

\section{Orthogonal Design Table and Results}

TABLE 12: Microparameters of orthogonal test.

\begin{tabular}{lcccccc}
\hline Plan & $E_{c}$ & $k_{\text {rat }}$ & $\mu$ & $\sigma_{b}$ & $c_{b}$ & $\Phi_{b}$ \\
\hline 1 & 20.00 & 2.00 & 0.40 & 12.00 & 110.00 & 15.00 \\
2 & 110.00 & 2.00 & 1.00 & 6.00 & 150.00 & 35.00 \\
3 & 20.00 & 1.00 & 0.20 & 6.00 & 70.00 & 5.00 \\
4 & 40.00 & 3.00 & 1.00 & 14.00 & 110.00 & 5.00 \\
5 & 20.00 & 2.50 & 1.00 & 10.00 & 130.00 & 45.00 \\
6 & 80.00 & 2.00 & 0.60 & 10.00 & 90.00 & 5.00 \\
7 & 110.00 & 2.50 & 0.60 & 14.00 & 70.00 & 15.00 \\
8 & 80.00 & 1.00 & 0.40 & 14.00 & 150.00 & 45.00 \\
9 & 40.00 & 2.00 & 0.80 & 8.00 & 70.00 & 45.00 \\
10 & 60.00 & 3.00 & 0.40 & 10.00 & 70.00 & 35.00 \\
11 & 60.00 & 2.00 & 0.20 & 14.00 & 130.00 & 25.00 \\
12 & 20.00 & 3.00 & 0.60 & 8.00 & 150.00 & 25.00 \\
13 & 80.00 & 3.00 & 0.80 & 6.00 & 130.00 & 15.00 \\
14 & 110.00 & 3.00 & 0.20 & 12.00 & 90.00 & 45.00 \\
15 & 110.00 & 1.50 & 0.40 & 8.00 & 130.00 & 5.00 \\
16 & 80.00 & 1.50 & 1.00 & 12.00 & 70.00 & 25.00 \\
17 & 40.00 & 1.50 & 0.20 & 10.00 & 150.00 & 15.00 \\
18 & 110.00 & 1.00 & 0.80 & 10.00 & 110.00 & 25.00 \\
19 & 60.00 & 2.50 & 0.80 & 12.00 & 150.00 & 5.00 \\
20 & 20.00 & 1.50 & 0.80 & 14.00 & 90.00 & 35.00 \\
21 & 80.00 & 2.50 & 0.20 & 8.00 & 110.00 & 35.00 \\
22 & 60.00 & 1.50 & 0.60 & 6.00 & 110.00 & 45.00 \\
23 & 60.00 & 1.00 & 1.00 & 8.00 & 90.00 & 15.00 \\
24 & 40.00 & 1.00 & 0.60 & 12.00 & 130.00 & 35.00 \\
25 & 40.00 & 2.50 & 0.40 & 6.00 & 90.00 & 25.00 \\
\hline & & & & & &
\end{tabular}

TABLE 13: Calculated macroparameters of orthogonal test.

\begin{tabular}{lcccccc}
\hline Plan & UCS & $E$ & $v$ & TS & $c$ & $\varphi$ \\
\hline 1 & 106.88 & 14.25 & 0.2284 & 9.807 & 19.90 & 49.40 \\
2 & 200.36 & 72.51 & 0.3986 & 4.96 & 33.54 & 53.10 \\
3 & 63.35 & 17.61 & 0.1074 & 5.93 & 19.31 & 29.06 \\
4 & 129.14 & 24.78 & 0.3519 & 10.43 & 29.25 & 42.55 \\
5 & 155.18 & 12.48 & 0.4105 & 7.75 & 27.45 & 52.43 \\
6 & 104.03 & 58.98 & 0.2012 & 8.17 & 25.52 & 39.12 \\
7 & 97.28 & 77.64 & 0.1963 & 10.83 & 24.23 & 38.46 \\
8 & 172.42 & 70.83 & 0.1108 & 8.42 & 36.36 & 45.22 \\
9 & 109.90 & 29.02 & 0.2393 & 6.56 & 17.70 & 56.28 \\
10 & 87.02 & 36.01 & 0.3577 & 7.41 & 19.30 & 44.00 \\
11 & 109.63 & 40.45 & 0.2712 & 11.42 & 24.05 & 44.16 \\
12 & 130.47 & 55.78 & 0.1073 & 5.95 & 25.44 & 49.13 \\
13 & 136.94 & 43.27 & 0.5526 & 4.41 & 27.81 & 47.21 \\
14 & 96.59 & 61.62 & 0.4252 & 8.86 & 20.63 & 45.47 \\
15 & 118.23 & 83.75 & 0.2174 & 6.98 & 27.02 & 42.04 \\
16 & 116.38 & 67.68 & 0.1085 & 10.61 & 24.75 & 44.48 \\
17 & 108.39 & 28.81 & 0.2592 & 8.789 & 23.30 & 45.19 \\
18 & 155.92 & 104.16 & 0.0686 & 9.88 & 37.77 & 39.27 \\
19 & 154.22 & 37.83 & 0.3760 & 9.30 & 32.35 & 45.72 \\
20 & 133.09 & 16.76 & 0.1200 & 12.03 & 29.36 & 43.67 \\
21 & 97.65 & 44.29 & 0.5010 & 6.19 & 21.25 & 44.72 \\
22 & 138.49 & 45.49 & 0.2425 & 5.23 & 26.45 & 49.71 \\
23 & 130.88 & 58.14 & 0.0563 & 7.86 & 32.75 & 37.74 \\
24 & 166.91 & 36.89 & 0.0861 & 9.56 & 37.11 & 43.12 \\
25 & 91.87 & 23.91 & 0.4128 & 4.61 & 20.36 & 44.06 \\
\hline & & & & & &
\end{tabular}

\section{Data Availability}

The data used to support the findings of this study are available from the corresponding author upon request.

\section{Conflicts of Interest}

The authors declare that there are no conflicts of interest regarding the publication of this paper.

\section{Acknowledgments}

This research was funded by the National Natural Science Foundation of China (grant no. 51034001).

\section{References}

[1] J. A. Hudson and J. P. Harrison, Engineering Rock Mechanics: An Introduction to the Principles, Elsevier, Oxford, UK, 2000.

[2] W. S. Dershowitz and H. H. Einstein, "Characterizing rock joint geometry with joint system models," Rock Mechanics and Rock Engineering, vol. 21, no. 1, pp. 21-51, 1988.

[3] G. B. Baecher, N. A. Lanney, and H. H. Einstein, "Statistical description of rock properties and sampling," in Proceedings of the 18th US Symposium on Rock Mechanics, American Rock Mechanics Association, New York, NY, USA, pp. 1-8, June 1977.

[4] G. B. Baecher, "Statistical analysis of rock mass fracturing," Journal of the International Association for Mathematical Geology, vol. 15, no. 2, pp. 329-348, 1983.

[5] J. A. Hudson and S. D. Priest, "Discontinuity frequency in rock masses," International Journal of Rock Mechanics and Mining Sciences \& Geomechanics Abstracts, vol. 20, no. 2, pp. 73-89, 1983.

[6] S. D. Priest and J. A. Hudson, "Discontinuity spacings in rock," International Journal of Rock Mechanics and Mining Sciences \& Geomechanics Abstracts, vol. 13, no. 5, pp. 135-148, 1976.

[7] S. D. Priest and J. A. Hudson, "Estimation of discontinuity spacing and trace length using scanline surveys," International Journal of Rock Mechanics and Mining Sciences \& Geomechanics Abstracts, vol. 18, no. 3, pp. 183-197, 1981.

[8] T. Rives, M. Razack, J.-P. Petit, and K. D. Rawnsley, "Joint spacing: analogue and numerical simulations," Journal of Structural Geology, vol. 14, no. 8-9, pp. 925-937, 1992.

[9] W. S. Dershowitz and H. H. Herda, "Interpretation of fracture spacing and intensity," in Proceedings of the 33rd U.S. Symposium on Rock Mechanics (USRMS), pp. 757-766, Santa Fe, NM, USA, June 1992.

[10] P. Davy, "On the frequency-length distribution of the san andreas fault system," Journal of Geophysical Research, vol. 98, pp. 925-937, 1993.

[11] E. Bonnet, O. Bour, N. E. Odling et al., "Scaling of fracture systems in geological media," Reviews of Geophysics, vol. 39, no. 3, pp. 347-383, 2001.

[12] C. A. Barton and M. D. Zoback, "Self-similar distribution and properties of macroscopic fractures at depth in crystalline rock in the cajon pass scientific drill hole," Journal of Geophysical Research, vol. 97, no. B4, pp. 5181-5200, 1992.

[13] J. N. Hooker, J. F. W. Gale, L. A. Gomez, S. E. Laubach, R. Marrett, and R. M. Reed, "Aperture-size scaling variations in a low-strain opening-mode fracture set, Cozzette Sandstone, Colorado," Journal of Structural Geology, vol. 31, no. 7, pp. 707-718, 2009. 
[14] H. H. Einstein and G. B. Baecher, "Probabilistic and statistical methods in engineering geology," Rock Mechanics and Rock Engineering, vol. 16, no. 1, pp. 39-72, 1983.

[15] R. E. Hammah and J. H. Curran, "Fuzzy cluster algorithm for the automatic identification of joint sets," International Journal of Rock Mechanics and Mining Sciences, vol. 35, no. 7, pp. 889-905, 1998.

[16] B. Lu, X.-L. Ding, and A.-Q. Wu, "Study on method of orientation data partitioning of randomly distributed discontinuities of rocks," Chinese Journal of Rock Mechanics and Engineering, vol. 26, no. 9, pp. 1809-1816, 2007, in Chinese.

[17] B. Tokhmechi, H. Memarian, B. Moshiri et al., "Investigating the validity of conventional joint set clustering methods," Engineering Geology, vol. 118, no. 3-4, pp. 75-81, 2011.

[18] L.-M. Xu, J.-P. Chen, Q. Wang et al., "Fuzzy c-means cluster analysis based on mutative scale chaos optimization algorithm for the grouping of discontinuity sets," Rock Mechanics and Rock Engineering, vol. 46, pp. 189-198, 2013.

[19] Y. Li, Q. Wang, J. Chen, L. Xu, and S. Song, "K-means algorithm based on particle swarm optimization for the identification of rock discontinuity sets," Rock Mechanics and Rock Engineering, vol. 48, no. 1, pp. 375-385, 2014.

[20] C. Wei, Y. Li, W. Zhu, S. Li, S. Wang, and H. Wang, "Experimental observation and numerical investigation on propagation and coalescence process of multiple flaws in rock-like materials subjected to hydraulic pressure and farfield stress," Theoretical and Applied Fracture Mechanics, vol. 108, p. 102603, 2020.

[21] J. Zheng, J. Deng, X. Yang, J. Wei, H. Zheng, and Y. Cui, “An improved Monte Carlo simulation method for discontinuity orientations based on fisher distribution and its program implementation," Computers and Geotechnics, vol. 61, pp. 266-276, 2014.

[22] Y. Li, H.-P. Wang, W.-B. Cai et al., "Stability monitoring of surrounding rock mass on a forked tunnel using both strain gauges and FBG sensors," Measurement, vol. 153, Article ID 107449, 2019.

[23] X. Xi, X. Wu, Q. Guo, and M. Cai, "Experimental investigation and numerical simulation on the crack initiation and propagation of rock with pre-existing cracks," IEEE Access, vol. 8, pp. 129636-129644, 2020.

[24] H. H. Einstein and J.-L. Z. Locsin, "Modeling rock fracture intersections and application to the Boston area," Journal of Geotechnical and Geoenvironmental Engineering, vol. 138, no. 11, pp. 1415-1421, 2012.

[25] V. M. Ivanova, R. Sousa, B. Murrihy, and H. H. Einstein, "Mathematical algorithm development and parametric studies with the GEOFRAC three-dimensional stochastic model of natural rock fracture systems," Computers \& Geosciences, vol. 67, pp. 100-109, 2014.

[26] P. A. Cundall and O. D. L. Strack, "Discussion: a discrete numerical model for granular assemblies," Géotechnique, vol. 30, no. 3, pp. 331-336, 1980.

[27] Itasca Consulting Group Inc, PFC (Version 5.0) manual, Itasca Consulting Group Inc, Minneapolis, MN, USA, 2014.

[28] D. O. Potyondy and P. A. Cundall, "A bonded-particle model for rock," International Journal of Rock Mechanics and Mining Sciences, vol. 41, no. 8, pp. 1329-1364, 2004.

[29] M. P. J. Schöpfer, S. Abe, C. Childs, and J. J. Walsh, "The impact of porosity and crack density on the elasticity, strength and friction of cohesive granular materials: insights from DEM modelling," International Journal of Rock Mechanics and Mining Sciences, vol. 46, no. 2, pp. 250-261, 2009.
[30] X. Ding and L. Zhang, "A new contact model to improve the simulated ratio of unconfined compressive strength to tensile strength in bonded particle models," International Journal of Rock Mechanics and Mining Sciences, vol. 69, no. 3, pp. 111-119, 2014.

[31] N. Cho, C. D. Martin, and D. C. Sego, "A clumped particle model for rock," International Journal of Rock Mechanics and Mining Sciences, vol. 44, no. 7, pp. 997-1010, 2007.

[32] D. O. Potyondy, "A flat-jointed bonded-particle material for hard rock," in Proceedings of the 46th US rock mechanics/ geomechanics symposium, pp. 1510-1519, Chicago, IL, USA, June 2012.

[33] D. M. Ivars, M. E. Pierce, C. Darcel et al., "The synthetic rock mass approach for jointed rock mass modelling," International Journal of Rock Mechanics and Mining Sciences, vol. 48, no. 2, pp. 219-244, 2011.

[34] M. E. Pierce, D. M. Ivars, D. O. Potyondy et al., "A synthetic rock mass model for jointed rock," in Proceedings of the 1st Canada-US Rock Mechanics Symposium-Rock Mechanics Meeting Society's Challenges and Demands, pp. 341-349, Vancouver, Canada, June 2007.

[35] J. A. Vallejos, K. Suzuki, A. Brzovic, and D. M. Ivars, “Application of Synthetic Rock Mass modeling to veined core-size samples," International Journal of Rock Mechanics and Mining Sciences, vol. 81, pp. 47-61, 2016.

[36] Y. Zhou, A. Misra, S.-C. Wu et al., "Macro- and meso-analyses of rock joint direct shear test using particle flow theory," Chinese Journal of Rock Mechanics and Engineering, vol. 31, no. 6, pp. 1245-1256, 2012, in Chinese.

[37] C.-C. Xia, S.-Y. Long, Z.-C. Tang et al., "Particle flow numerical simulation for shear behavior of rough joints," Chinese Journal of Rock Mechanics and Engineering, vol. 31, no. 8, pp. 1545-1552, 2012, in Chinese.

[38] M. Bahaaddini, G. Sharrock, and B. K. Hebblewhite, "Numerical direct shear tests to model the shear behaviour of rock joints," Computers and Geotechnics, vol. 51, pp. 101-115, 2013.

[39] X.-R. Liu, Z.-Y. Deng, Y.-Q. Liu et al., "Macroscopic and microscopic analysis of particle flow in pre-peak cyclic direct shear test of rock joint," Journal of China Coal Society, vol. 44, no. 7, pp. 2103-2115, 2019, in Chinese.

[40] C.-C. Chiu, T.-T. Wang, M.-C. Weng, and T.-H. Huang, "Modeling the anisotropic behavior of jointed rock mass using a modified smooth-joint model," International Journal of Rock Mechanics and Mining Sciences, vol. 62, pp. 14-22, 2013.

[41] Y. Zhou, S.-C. Wu, Y.-T. Gao, and A. Misra, "Macro and meso analysis of jointed rock mass triaxial compression test by using equivalent rock mass (ERM) technique," Journal of Central South University, vol. 21, no. 3, pp. 1125-1135, 2014.

[42] M. Bahaaddini, G. Sharrock, and B. K. Hebblewhite, "Numerical investigation of the effect of joint geometrical parameters on the mechanical properties of a non-persistent jointed rock mass under uniaxial compression," Computers and Geotechnics, vol. 49, pp. 206-225, 2013.

[43] K. Esmaieli, J. Hadjigeorgiou, and M. Grenon, "Estimating geometrical and mechanical REV based on synthetic rock mass models at brunswick, mine," International Journal of Rock Mechanics and Mining Sciences, vol. 47, no. 6, pp. 915-926, 2010.

[44] Y. Zhou, L. Wang, J.-F. Ding et al., "Particle flow code analysis of multi-scale jointed rock mass based upon equivalent rock mass technique," Rock and Soil Mechanics, vol. 37, no. 7, pp. 2085-2095, 2016, in Chinese.

[45] J. A. Vallejos, K. Suzuki, A. Brzovic et al., "Characterization and synthetic simulations to determine rock mass behavior at the El Teniente mine, Chile. part II," in Proceedings of Caving, pp. 1-9, Santiago, Chile, June 2014. 
[46] C.-C. Ma, T.-B. Li, H.-L. Xing et al., "Brittle rock modeling approach and its validation using excavation-induced microseismicity," Rock Mechanics and Rock Engineering, vol. 49, no. 8, pp. 3175-3188, 2016.

[47] M. E. Pierce and C. Fairhurst, "Synthetic rock mass applications in mass mining," in Harmonising Rock Engineering and the Environment - Proceedings of the 12th ISRM International Congress on Rock Mechanics, pp. 109-114, London, UK, October 2011.

[48] J. Hadjigeorgiou, K. Esmaieli, and M. Grenon, "Stability analysis of vertical excavations in hard rock by integrating a fracture system into a PFC model," Tunnelling and Underground Space Technology, vol. 24, no. 3, pp. 296-308, 2009.

[49] Q.-H. Li, J. P. Latham, and C.-F. Tsang, "The use of discrete fracture networks for modelling coupled geomechanical and hydrological behavior of fractured rocks," Computers and Geotechnics, vol. 85, pp. 151-176, 2017.

[50] F.-Q. Wu, S.-J. Wang, S.-W. Song et al., "Statistical methods and theories in rock mechanics," Chinese Science Bulletin, vol. 38, no. 15, pp. 1345-1354, 1993, in Chinese.

[51] Y. Zhou, G. Han, S.-C. Wu et al., "Meso failure mechanism of rock mass and slope with intermittent joints," Chinese Journal of Rock Mechanics and Engineering, vol. 35, no. 2, pp. 3878-3889, 2016.

[52] S.-C. Wu, Y. Zhou, L.-L. Gao et al., "Application of equivalent rock mass technique to rock mass engineering," Chinese Journal of Rock Mechanics and Engineering, vol. 29, no. 7, pp. 1435-1441, 2010, in Chinese.

[53] X.-T. Yin, Y.-N. Zheng, and S.-K. Ma, "Study of inner scale ratio of rock and soil material based on numerical tests of particle flow code," Rock and Soil Mechanics, vol. 32, no. 4, pp. 1211-1215, 2011, in Chinese.

[54] X.-B. Ding, L.-Y. Zhang, H.-H. Zhu et al., "Effect of model scale and particle size distribution on pfc3d simulation results," Rock Mechanics and Rock Engineering, vol. 47, no. 6, pp. 1-18, 2013.

[55] S. Wu and X. Xu, "A study of three intrinsic problems of the classic discrete element method using flat-joint model," Rock Mechanics and Rock Engineering, vol. 49, no. 5, pp. 1813-1830, 2016. 